\title{
Electrochemical Engineering of Nanoporous Materials for Photocatalysis: Fundamentals, Advances, and Perspectives
}

\author{
Siew Yee Lim ${ }^{1,2,3}$, Cheryl Suwen Law ${ }^{1,2,3}$ (D) Lina Liu 1,4,5, Marijana Markovic ${ }^{1,6}$, \\ Carina Hedrich ${ }^{7}$, Robert H. Blick ${ }^{7}$, Andrew D. Abell ${ }^{2,3,8}$, Robert Zierold ${ }^{7, *(1)}$ \\ and Abel Santos 1,2,3,*(D) \\ 1 School of Chemical Engineering and Advanced Materials, The University of Adelaide, \\ Adelaide, SA 5005, Australia; siewyee.lim@adelaide.edu.au (S.Y.L.); suwen.law@adelaide.edu.au (C.S.L.); \\ lina.liu@adelaide.edu.au (L.L.); marijana.markovic@adelaide.edu.au (M.M.) \\ 2 Institute for Photonics and Advanced Sensing (IPAS), The University of Adelaide, \\ Adelaide, SA 5005, Australia; andrew.abell@adelaide.edu.au \\ 3 ARC Centre of Excellence for Nanoscale BioPhotonics (CNBP), The University of Adelaide, \\ Adelaide, SA 5005, Australia \\ 4 School of Chemistry and Chemical Engineering, Ningxia University, Yinchuan 750021, China \\ 5 State Key Laboratory of High-Efficiency Utilization of Coal and Green Chemical Engineering, \\ Ningxia University, Yinchuan 750021, China \\ 6 School of Agriculture Food and Wine, The University of Adelaide, Adelaide, SA 5064, Australia \\ 7 Center for Hybrid Nanostructures, Universität Hamburg, 22761 Hamburg, Germany; \\ chedrich@physnet.uni-hamburg.de (C.H.); rblick@chyn.uni-hamburg.de (R.H.B.) \\ 8 Department of Chemistry, The University of Adelaide, Adelaide, SA 5005, Australia \\ * Correspondence: rzierold@physnet.uni-hamburg.de (R.Z.); abel.santos@adelaide.edu.au (A.S.); \\ Tel.: +49-40-42838-1594 (R.Z.); Tel.: +61-8-8313-1535 (A.S.)
}

Received: 14 November 2019; Accepted: 23 November 2019; Published: 25 November 2019

\begin{abstract}
Photocatalysis comprises a variety of light-driven processes in which solar energy is converted into green chemical energy to drive reactions such as water splitting for hydrogen energy generation, degradation of environmental pollutants, $\mathrm{CO}_{2}$ reduction and $\mathrm{NH}_{3}$ production. Electrochemically engineered nanoporous materials are attractive photocatalyst platforms for a plethora of applications due to their large effective surface area, highly controllable and tuneable light-harvesting capabilities, efficient charge carrier separation and enhanced diffusion of reactive species. Such tailor-made nanoporous substrates with rational chemical and structural designs provide new exciting opportunities to develop advanced optical semiconductor structures capable of performing precise and versatile control over light-matter interactions to harness electromagnetic waves with unprecedented high efficiency and selectivity for photocatalysis. This review introduces fundamental developments and recent advances of electrochemically engineered nanoporous materials and their application as platforms for photocatalysis, with a final prospective outlook about this dynamic field.
\end{abstract}

Keywords: photocatalysis; nanoporous materials; anodization; chemical modification; structural engineering; optical nanostructures

\section{Introduction}

Solar light is one of the most promising green energy resources, which can theoretically provide more than enough energy to address emerging global challenges such as climate change 
and environmental pollution. Heterogeneous photocatalysis-henceforth "photocatalysis"—is a light-driven process in which photons (light-electromagnetic waves) interact with atoms (matter-semiconductor) to generate electron-hole $\left(\mathrm{e}^{-} / \mathrm{h}^{+}\right)$pairs (charge carriers) that produce free radicals able to undergo secondary reactions. Photocatalytic processes involve a photoactive material (e.g., semiconductor, noble metal) with a well-defined energy bandgap [1]. When the energy of the incoming photons is higher than the energy bandgap of the platform material, electrons and holes are generated in the material's conduction and valence bands, respectively [1]. $\mathrm{e}^{-} / \mathrm{h}^{+}$pairs can subsequently produce non-selective free radicals (i.e., $\cdot \mathrm{OH}$ radicals) on the surface of the material upon reaction with red-ox species in the surrounding media, enabling secondary chemical reaction paths for different applications, including energy generation and environmental remediation. This light-driven process can either be carried out under open-circuit conditions (i.e., photocatalysis) or under applied electrochemical bias (i.e., photo-electrocatalysis). The seminal study demonstrating clean hydrogen $\left(\mathrm{H}_{2}\right)$ fuel generation by water splitting on titanium dioxide $\left(\mathrm{TiO}_{2}\right)$ under $\mathrm{UV}$ light irradiation by Fujishima and Honda in 1972 stimulated intensive research activity in this field [2]. Currently, photocatalysis comprises a wide range of light-driven chemical reactions, including degradation of pollutants [3,4], air purification $[5,6]$, clean $\mathrm{H}_{2}$ energy generation $[7,8]$, carbon dioxide $\left(\mathrm{CO}_{2}\right)$ reduction $[9,10]$, ammonia $\left(\mathrm{NH}_{3}\right)$ production $[11,12]$ and organic synthesis $[13,14]$. However, conventional photocatalyst materials have inherent constraints such as low photon-to-electron conversion rates due to limited utilization of high-irradiance solar spectral regions (e.g., $43 \%$ visible) and low effective surface area [15]. Therefore, fundamental understanding and engineering of light-matter interactions at the nanoscale along with smart chemical and structural designs of photocatalysts can provide new paths to maximize the efficiency of photocatalytic reactions for future breakthrough technologies.

Typically, in order to enhance photocatalytic reactions and achieve maximum photocatalytic efficiencies, the structure of the photocatalyst platform is engineered to a high specific surface area to increase the number of active sites for red-ox reactions. Such adaptation is often achieved by engineering photocatalysts in the form of nanoparticle-based systems, which are either suspended in the reaction media or compacted into a photoelectrode [16]. However, nanoparticulate systems are susceptible to aggregation, poor electronic properties caused by band bending, photobleaching, feature structural defects and have high charge carrier recombination rates [15]. Furthermore, practical use of nanoparticulate systems in photocatalysis has environmental and health regulatory challenges (i.e., uncertainty about the fate and toxicity of nanomaterials), which prevent the bench-to-field translation of this technology. Although photocatalysts in the form of thin films can overcome the drawbacks associated with nanoparticulate systems due to their robustness and integrability into fixed-bed photocatalytic reactors, these photocatalyst systems often show a reduced efficiency compared to their nanoparticle counterparts due to their low surface area, which allows only one species (either $\mathrm{e}^{-}$or $\mathrm{h}^{+}$) to be available for reaction [17]. Significant efforts have been devoted to enhance performance of photocatalyst platforms by modifying their crystal structure [18,19], decoration with nanoparticles [20,21], co-deposition via sol-gel [22-25], atomic layer deposition [26,27], physical vapor [28,29] as well as electrochemical deposition [30,31], and doping [32,33]. The efficiency of photocatalysts can also be enhanced by engineering their structure at the nanoscale in the form of nanoporous photonic crystals (PC), which provide high specific surface area, enhanced utilization of incoming photons, and efficient mass transport of ionic and molecular species involved in photocatalytic reactions [22-25,34-43]. Inverse opal PC photocatalysts feature a characteristic photonic stopband (PSB) that can be engineered with precision across the spectral regions to harvest incoming photons from high-irradiance spectral regions [39-43]. Although these PC structures have been extensively explored as platform material for photocatalysis, they present several inherent drawbacks, including long fabrication process ( $>24 \mathrm{~h}$ ), restriction to 3D nanostructures, constraints to small domain areas and formation of structural defects [44].

Among other alternatives, electrochemically engineered nanoporous materials (EENMs) are promising photocatalyst platforms due to their versatile, highly controllable and self-organized 
nanoporous structure [18-38]. Advances in electrochemical oxidation (anodization) of valve metals such as aluminium and titanium enable new opportunities to precisely modulate and engineer the effective medium of semiconductor oxides to harness light-matter interactions for photocatalysis. Nanoporous anodic films can be produced with well-defined straight cylindrical nanopores or nanotubes as well as other advanced PC structures [45,46]. EENMs can also be produced with a unique set of physical and chemical properties, including chemical resistance, thermal stability, mechanical robustness, optoelectronic properties and large specific surface area, all of which are essential prerequisites to achieve high-performance photocatalytic devices $[37,45]$. In this context, this review provides a comprehensive perspective on recent advances in non-structurally and structurally engineered nanoporous photocatalyst materials produced by anodization (Figure 1). Electrochemical fabrication processes are first introduced, followed by a detailed description of chemical and structural modifications used to enhance the photocatalytic efficiency of these systems. We also provide an overview of the current state of the photocatalytic capabilities of electrochemically engineered nanoporous materials. Finally, this review concludes with a general overview and a prospective outlook on future trends in this field.

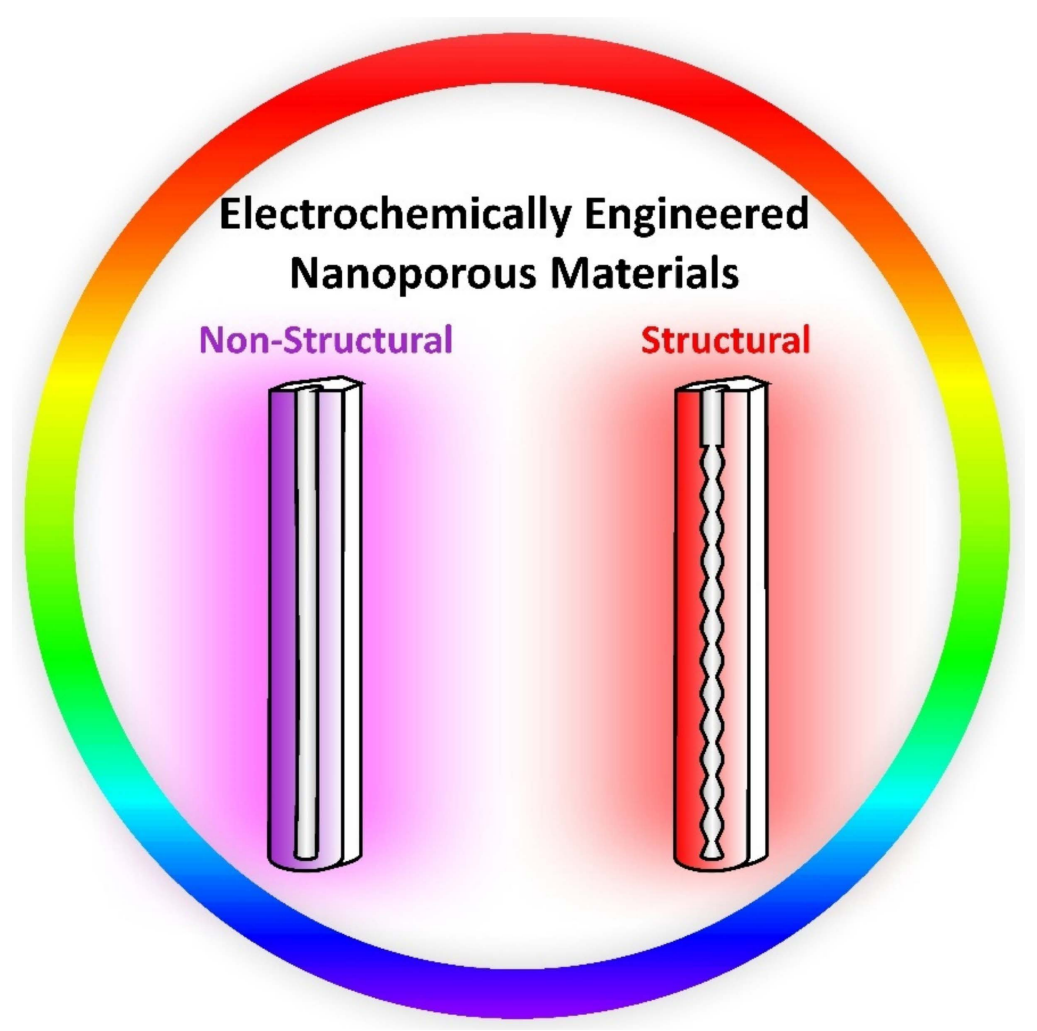

Figure 1. Electrochemically engineered nanoporous materials as photoactive platforms featuring non-structural and structural modifications to control light-matter interaction for photocatalysis.

\section{Electrochemical Engineering of Nanoporous Materials}

Anodization is an electrochemically driven oxidation process traditionally employed in the metal finishing industry to decorate metal surfaces and to protect them from corrosion [47]. During anodization, a passive layer of anodic metal oxide is produced on the metal surface, the morphology of which can either be nanoporous or compact non-porous. The ground-breaking discovery of self-organized nanoporous anodic alumina $\left(\mathrm{Al}_{2} \mathrm{O}_{3}\right)$ in 1995 [48] stimulated an intensive research activity in anodization of valve metals (i.e., $\mathrm{Al}, \mathrm{Ti}, \mathrm{Fe}, \mathrm{W}, \mathrm{Zr}, \mathrm{Nb}, \mathrm{Hf}, \mathrm{V}$ and $\mathrm{Co}$ ) [49-68].

Anodization of valve metals is generally performed in a temperature-controlled electrochemical cell, in which two electrodes (i.e., anode $=\operatorname{valve}$ metal $(\mathrm{M})$ and cathode $=$ platinum $(\mathrm{Pt})$ ) are submerged in an electrolyte (Figure 2a) [69]. When the cell is externally supplied either by constant potential (i.e., 
potentiostatic oxidation) or by constant current (i.e., galvanostatic oxidation), an oxidation reaction $\mathrm{M} \rightarrow \mathrm{M}^{\mathrm{z}+}+\mathrm{z} \mathrm{e}^{-}$is initiated. Depending on the main anodization parameters (i.e., voltage/current, temperature and electrolyte), three possible reactions exist: (i) the metal is continuously dissolved to produce $\mathrm{M}^{\mathrm{Z}+}$ ions (soluble anodic oxide); (ii) $\mathrm{M}^{\mathrm{Z}+}$ ions react with $\mathrm{O}^{2-}$ from $\mathrm{H}_{2} \mathrm{O}$ in the electrolyte and form compact non-porous oxide (MO) (non-soluble anodic oxide); and (iii) competition between formation and dissolution of oxide occurs, leading to the formation of nanoporous $\mathrm{MO}$ structures (partially soluble anodic oxide). Under specific experimental conditions for certain valve metals, (iv) disorganized rapid growth of bundles of nanopores/nanotubes, and (v) formation of thick self-organized mesoporous structures can occur.
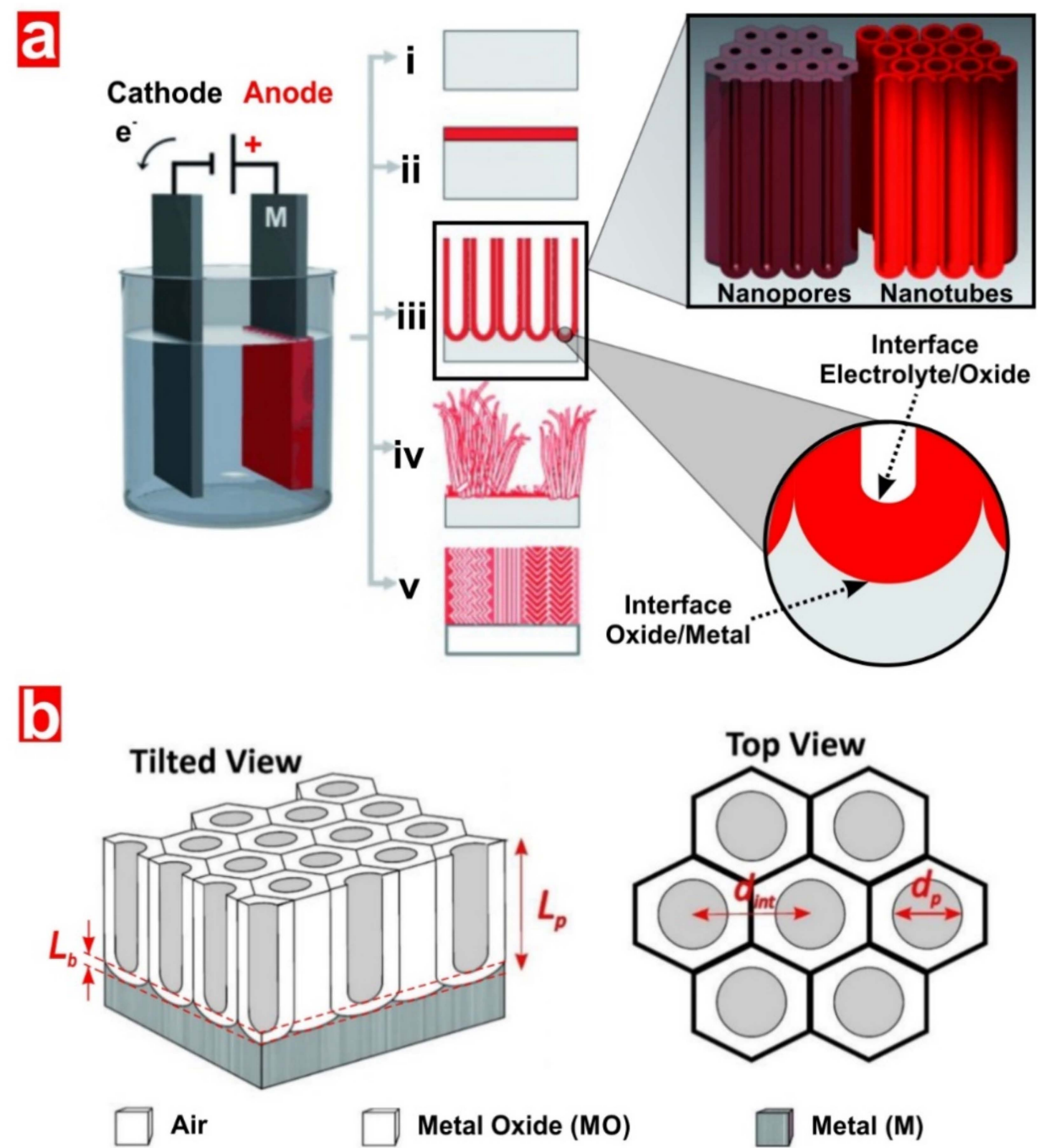

Figure 2. Fabrication of electrochemically engineered nanoporous materials (EENMs). (a) Schematic diagram illustrating the electrochemical anodization process, details of the oxide barrier layer located at the bottom tip of the nanostructures and possible anodic morphologies: (i) metal electropolishing; (ii) formation of compact anodic oxides; (iii) self-organized oxides (nanopores or nanotubes); (iv) rapid (disorganized) oxide nanotube formation; and (v) ordered nanoporous layers. Reproduced from [69], with copyright permission from Wiley-VCH Verlag GmbH \& Co. KGaA, Weinheim, 2011. (b) Structural and geometric features of EENMs produced by anodization with tilted view of an EENM (left) ( $L_{p}$-nanopore length and $L_{b}$-barrier layer thickness) and top view of EENMs (right) ( $d_{\text {int }}$-interpore distance and $d_{p}$-nanopore diameter). Reproduced from [70], with copyright permission from MDPI, 2018. 
Anodization is a highly versatile 3D nanofabrication approach, which can be applied to multiple metal substrates. Fabrication of nanoporous anodic alumina (NAA) structures by electrochemical oxidation of aluminium is the most developed anodization technology as compared to other metal oxides due to its controllability and well-defined nanoporous geometry [45]. However, there is a significant progress in anodization of other valve metals such as $\mathrm{Ti}, \mathrm{Fe}, \mathrm{W}, \mathrm{Zr}, \mathrm{Nb}, \mathrm{Hf}, \mathrm{V}$ and Co. Efforts have been made to develop Ti anodization technology due to the high stability against photo-corrosion and excellent optoelectronic properties for photocatalysis of anodic titanium dioxide $\left(\mathrm{TiO}_{2}\right)$ structures $[16,37,69]$. Anodization of valve metals under suitable conditions can result in anodic films featuring ordered nanopores or nanotubes with high aspect ratio. Figure $2 b$ shows a graphic definition of the structural features of nanopore/nanotube geometry such as diameter $\left(d_{p}\right)$, pore length $\left(L_{p}\right)$, interpore distance $\left(d_{\text {int }}\right)$ and barrier layer thickness $\left(L_{b}\right)$. These characteristics can be precisely engineered by controlled manipulation of the anodization parameters [70]. The most representative examples of the self-organizing anodization conditions (i.e., voltage $(\mathrm{V})$, temperature $(\mathrm{T})$, electrolyte type) and main structural features (i.e., $d_{p}$ ) for multiple valve metals are summarized in Table 1 . These studies demonstrate the fabrication of highly controllable nanoporous or nanotubular structures of various metal oxides through simple modification of the anodization parameters. For most of the valve metals, the presence of fluoride (F-) ions in the acid electrolyte is key in the formation of nanoporous or nanotubular structures due to the high chemical stability of their anodic oxides.

Table 1. Summary of self-organizing conditions and structural features of nanopores or nanotubes obtained by anodization of various valve metals.

\begin{tabular}{|c|c|c|c|c|c|}
\hline Ref. & Valve Metal & Electrolyte Type & $\mathrm{T}\left({ }^{\circ} \mathrm{C}\right)$ & $V(V)$ & $d_{p}(n m)$ \\
\hline$[49,50]$ & $\mathrm{Al}$ & Diluted $\mathrm{H}_{2} \mathrm{SO}_{4}$ & $0-5$ & $25-40$ & $25-30$ \\
\hline$[48,51]$ & & Diluted $\mathrm{C}_{2} \mathrm{H}_{2} \mathrm{O}_{4}$ & $0-8$ & $40-140$ & $30-50$ \\
\hline [52] & & Diluted $\mathrm{H}_{3} \mathrm{PO}_{4}$ & $0-1$ & 195 & 500 \\
\hline [53] & $\mathrm{Ti}$ & Buffered neutral electrolyte with $\mathrm{F}^{-}$salts & 20 & 20 & 100 \\
\hline$[54,55]$ & & Organic solvent with $\mathrm{F}^{-}$salts & 20 & 60 & $120-150$ \\
\hline$[56,57]$ & & $\mathrm{Cl}^{-}$-containing electrolyte & $4-20$ & $10-60$ & $15-40$ \\
\hline$[58,59]$ & & Ethylene glycol with $\mathrm{F}^{-}$salts and $\mathrm{H}_{2} \mathrm{O}$ & 20 & $30-50$ & $38-174$ \\
\hline$[60,61]$ & $\mathrm{Fe}$ & Ethylene glycol with $\mathrm{NH}_{4} \mathrm{~F}$ and $\mathrm{H}_{2} \mathrm{O}$ & 20 & $20-100$ & $50-110$ \\
\hline [62] & $\mathrm{Zr}$ & Ethylene glycol with $\mathrm{NH}_{4} \mathrm{~F}$ and $\mathrm{H}_{2} \mathrm{O}$ & 20 & $20-100$ & $70-120$ \\
\hline [57] & $\mathrm{W}$ & $\mathrm{Cl}^{-}$-containing electrolyte & 4 & $50-80$ & $30-50$ \\
\hline [63] & & Diluted $\mathrm{NaF}$ & 20 & $20-60$ & 100 \\
\hline [64] & $\mathrm{Nb}$ & Diluted $\mathrm{H}_{3} \mathrm{PO}_{4}$ with $\mathrm{HF}$ & 20 & $1-5$ & $8-12$ \\
\hline [65] & & Glycerol with $\mathrm{NH}_{4} \mathrm{~F}$ and $\mathrm{H}_{2} \mathrm{O}$ & 20 & $20-60$ & 50 \\
\hline [66] & $\mathrm{Hf}$ & Diluted $\mathrm{H}_{2} \mathrm{SO}_{4}$ with $\mathrm{HF}$ & 20 & $10-60$ & $15-90$ \\
\hline [67] & $\mathrm{V}$ & {$\left[\mathrm{BF}_{4}\right]^{-}$or $\left[\mathrm{TiF}_{6}\right]^{2-}$-based electrolyte } & 20 & $40-300$ & $10-30$ \\
\hline [68] & Co & Ethylene glycol with $\mathrm{NH}_{4} \mathrm{~F}$ and $\mathrm{H}_{2} \mathrm{O}$ & 0 & 50 & 100 \\
\hline
\end{tabular}

\section{Chemical Modification of Electrochemically Engineered Nanoporous Materials}

The chemical structure of EENMs is often modified with different entities (e.g., metals, quantum dots, semiconductor oxide films, conducting polymers, chalcogenides) to tune their optical, electrical and chemical properties to achieve desired functionalities and performances for specific photocatalytic and photo-electrocatalytic applications $[37,69,71]$.

\subsection{Doping}

The chemical composition of EENMs can be altered by doping or bandgap engineering to enhance their performance in photocatalysis. Doping involves the introduction of secondary electronically active species into the crystal lattice of EENMs in order to modify the electrical conductivity and narrow the optical bandgap of the anodic oxide [72,73]. The intermediate states introduced from the doping elements (i.e., dopants) are required to be considerably close to the band edges (i.e., conduction or valence bands) of the anodic oxide for successful modification. The relative positions of 
dopants to the band edges of the intrinsic photocatalyst material can be estimated by the density of states (DOS) calculations [16,37]. Strategies to dope the chemical composition of EENMs include the implantation of non-metal (C, N, B and F) [33,74-77] and metal ( $\mathrm{Cu}$ and lanthanides) $[78,79]$ elements, which are introduced by thermal treatment (annealing) in the gas atmosphere of the dopant element, co-sputtering or sputtering in dopant atmosphere, treatment in solution or melt of dopant, and high-energy ion implantation [69].

The most widespread doping approach is N-doping via ion implantation, which has been demonstrated to be particularly successful to incorporate nitrogen-containing species into as-produced $\mathrm{TiO}_{2}$ nanotube structures at low-to-medium doping levels $\left(1 \times 10^{16}\right.$ ions $\left.\mathrm{cm}^{-2}\right)[75,80]$. However, this doping method is limited by the short ion penetration depth, recrystallization requirement and inhomogeneous dopant distribution across the inner and top surface of EENMs [37,81,82]. Despite these constraints, well-defined buried junctions can be created into the inner surface of EENMs by rational utilization of the implantation profiles [80].

A particular straightforward doping approach to modify the chemical structure of EENMs in-situ the anodization process is using a metal alloy as a substrate. The alloy can either be prepared by arc melting or by co-sputtering of the pure valve metal and dopant metal [37]. Alloys can then be anodized to produce metal-doped EENMs. For instance, $\mathrm{TiO}_{2}$ nanotubular structures doped with $\mathrm{N}$ [83], $\mathrm{W}$ [84,85], Mo [4], Nb [7], Ta [86], Ru [87,88] and noble metal [89] fabricated by anodization of different alloy substrates have been demonstrated. These electrochemically synthesized doped anodic oxides have shown improved open-circuit photocatalytic (OCP) and photo-electrochemical (PEC) activities. Enhancement effects have been ascribed to modification of the band- or surface-state distribution, increase in conductivity, functionality as a co-catalyst or localized surface plasmon resonance (LSPR). Although considerable efforts have gone into solution-based doping approaches (i.e., ion incorporation from the anodization electrolyte during anodization) for P [90] and N [91], efforts targeting N-doping are questionable due to XPS peaks located at $400 \mathrm{eV}$ (adsorbed species), which were mostly obtained for nitrogen and unclarified electronic coupling of the doping species [69]. Though doping the structure of EENMs with non-metal and metal elements can be a suitable approach to increase the photocatalytic activity of these anodic oxides, the overall conversion efficiencies are often limited by thermal instability, decrease in charge carrier lifetime and unreliability of bandgap engineering [92]. Recent studies have demonstrated that visible light photo-response of EENMs for photocatalysis can be further enhanced by co-doping with a suitable combination of metals and/or non-metals $[3,93,94]$. For example, Yan et al. demonstrated enhanced photocatalytic and PEC properties under visible light irradiation by the synergetic effect in $\mathrm{TiO}_{2}$ nanotubes co-doped with $\mathrm{N}$ and $\mathrm{S}$ (Figure 3a) [3]. These $\mathrm{TiO}_{2}$ nanostructures were prepared by a combination of two-step anodization and treatment with thiourea and calcination under vacuum at $500{ }^{\circ} \mathrm{C}$ for $3 \mathrm{~h}$.

Reduction or annealing treatment under atmospheric pressure of $\mathrm{TiO}_{2}$-based EENMs can result in self-doping of $\mathrm{TiO}_{2}$ nanotubes by the formation of $\mathrm{Ti}^{3+} / \mathrm{Ov}$ (oxygen vacancy) lattice defects [37]. $\mathrm{Ti}^{3+}$ formation is beneficial to improve visible light photoresponse, increasing conductivity for improved charge separation and formation of surface states that facilitate charge transfer. This approach has been demonstrated as an optimal means of improving photocatalytic and PEC performances in reduced $\mathrm{TiO}_{2}$ nanotubes $[8,95,96]$. Liu et al. showed that $\mathrm{TiO}_{2}$ nanotubes exposed to high-pressure hydrogen treatment can produce reduced (black) $\mathrm{TiO}_{2}$ nanotubes for OCP photocatalytic $\mathrm{H}_{2}$ evolution without the need of co-catalysts (Figure 3b) [8]. Ion implantation of $\mathrm{H}$ and $\mathrm{N}$ into reduced $\mathrm{TiO}_{2}$ nanotubes can further enhance noble metal-free photocatalytic $\mathrm{H}_{2}$ generation by co-catalytic effect $[97,98]$. Despite the advantages of $\mathrm{Ti}^{3+}$, the surface states of $\mathrm{Ti}^{3+}$ are less stable and can readily be oxidized by air. Nevertheless, it has been reported that $\mathrm{Ti}^{3+}$ states in anatase can stabilize these configurations [99]. 

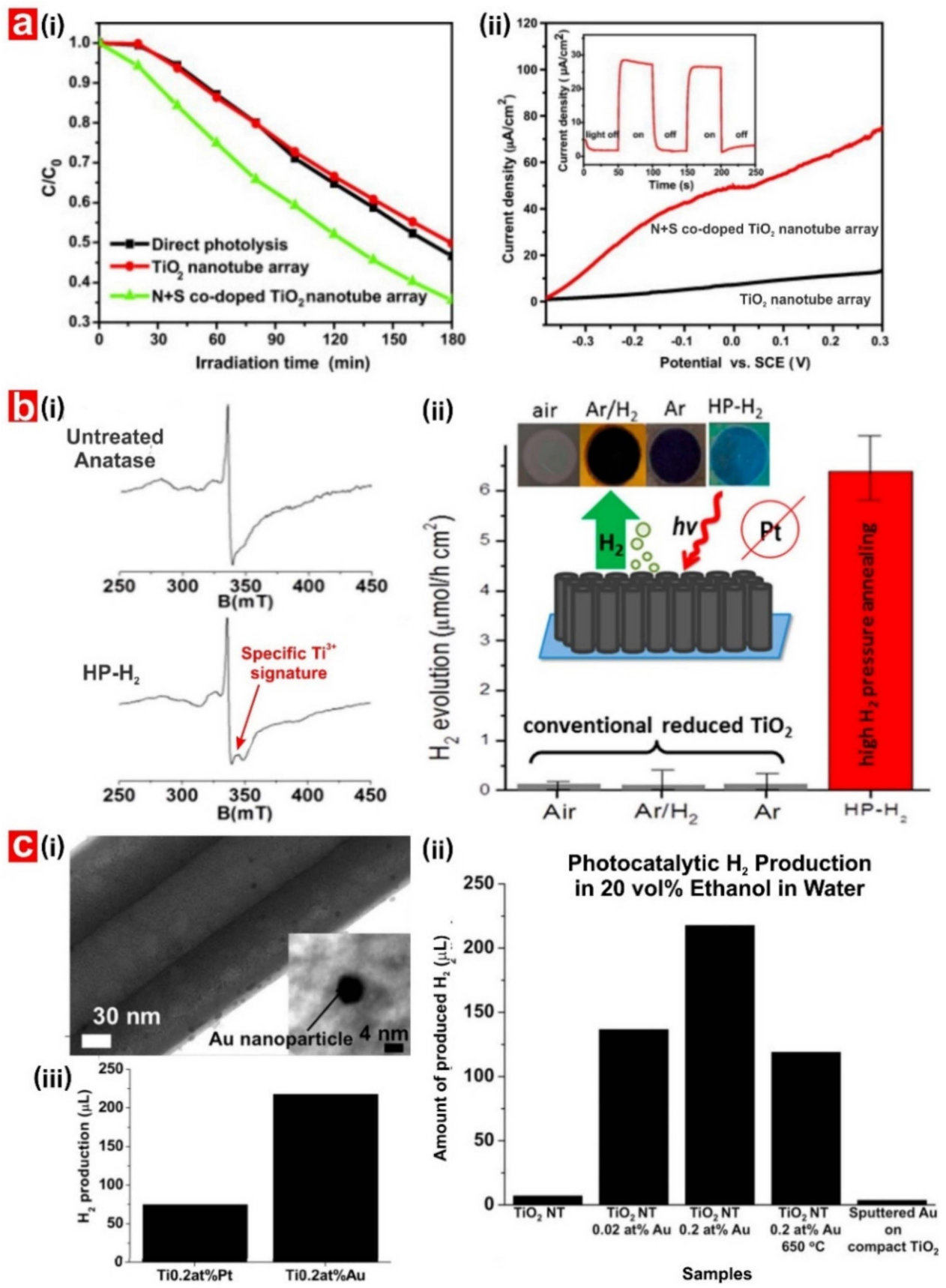

Figure 3. Examples of applicability of chemically-modified $\mathrm{TiO}_{2}$ nanotubes in photocatalytic and photo-electrocatalytic applications. (a) (i) Photodegradation kinetics of methylene blue (MB) and (ii) photo-electrochemical properties for pristine and $\mathrm{N}, \mathrm{S}$ co-doped $\mathrm{TiO}_{2}$ nanotubes under visible light irradiation. Reproduced from [3], with copyright permission from Elsevier B.V., 2011. (b) (i) EPR spectra for anatase and hydrogenated anatase $\mathrm{TiO}_{2}$ nanotubes and (ii) noble metal-free photocatalytic $\mathrm{H}_{2}$ generation under open circuit conditions in methanol/water (50/50 vol\%) using $\mathrm{TiO}_{2}$ nanotubes heat-treated in different atmospheres (air at $450{ }^{\circ} \mathrm{C}$; $\mathrm{Ar}$ at $500{ }^{\circ} \mathrm{C}$; $\mathrm{Ar} / \mathrm{H}_{2}$ at $500{ }^{\circ} \mathrm{C} ; \mathrm{HP}-\mathrm{H}_{2}$, heat treatment in $\mathrm{H}_{2}$ at 20 bar at $500{ }^{\circ} \mathrm{C}$ ). Reproduced from [37], with copyright permission from American Chemical Society, 2017. (c) (i) TEM image of self-decorated nanotubes formed by anodizing a Ti-Au alloy $(0.2 \mathrm{at}-\% \mathrm{Au})$; (ii) photocatalytic $\mathrm{H}_{2}$ production activities for different Ti-Au alloys and reference samples in $20 \mathrm{vol} \%$ ethanol in water; and (iii) photocatalytic $\mathrm{H}_{2}$ evolution with different types of noble metal on $\mathrm{TiO}_{2}$ nanotubes. Reproduced from [20], with copyright permission from Wiley-VCH Verlag GmbH \& Co. KGaA, Weinheim, 2013. 


\subsection{Physical Vapour Deposition (PVD)}

Physical vapour deposition (PVD) is an atomistic deposition process in which atoms or molecules of material are physically vaporized and transported through a vacuum or low pressure gaseous (or plasma) environment to form a thin film on the surface of EENMs by condensation [100]. Although PVD produces a non-conformal coating of deposited materials on EENMs, the deposition process is relatively inexpensive. PVD is typically used to deposit films elements, alloys and compounds with thicknesses in the range of a few nano-s to micrometres. PVD is categorized into five main categories, including electron beam evaporation, molecular beam epitaxy, pulsed laser deposition, sputtering and thermal deposition [101]. Ag, Au, Pt, W, Mo, Ni, Cu, semiconductor oxides and quantum dots are often deposited into nanoporous materials by thermal evaporation [102], sputter deposition $[21,28,29,89,103-105]$ or pulsed laser deposition [106] to improve photocatalytic and PEC performances by extending the lifetime of photogenerated charge carriers, narrowing the bandgap or by integrating LSPR effects. Nanoporous materials, such as NAA, can also be used as templates to produce various nanostructured materials (i.e., nanorods, nanowires and nanotubes) in combination with PVD processes. The resulting nanostructures have broad applicability in photocatalysis and the NAA templates can either be selectively removed or kept after the deposition process [101].

\subsection{Electrochemical Deposition (ECD)}

Electrochemical deposition (ECD)—commonly known as electrodeposition—is compared to the other deposition techniques a relatively simple and inexpensive deposition method where a solid coating on the surface of conductive EENMs is produced from ionic electrolytes under current/voltage-driven electrochemical reduction reactions [107]. Although ECD is limited by low deposition rate and single use of host template, this process is cost-effective, environmentally friendly and can be performed in any wet chemistry laboratory $[72,101,107]$. Various metals $[35,108]$, oxides $[30,109,110]$ and sulphides [31] can be electrodeposited to enhance the properties of EENMs for photocatalysis applications, including conductivity, chemical stability, PEC and photocatalytic properties [71].

\subsection{Atomic Layer Deposition (ALD)}

Atomic layer deposition (ALD) is a chemical gas phase technique used to deposit thin layers of materials such as oxides, nitrides, phosphates, sulphides and metals onto the entire surface of EENMs [111]. By this approach, the inner surface of EENMs is coated with atomic layers of an arbitrary material by repeating cyclic exposures to precursors and reactants, and purging. This method enables the precise control over the thickness and composition of the deposited film at the atomic scale, allowing the formation of homogeneous monolayers of the deposited material over large surfaces and high aspect ratios [112]. Nevertheless, the slow deposition rate, challenges in theoretical modelling of reactions and film growth, and potential cross-contamination of thin films by residual precursors can limit the application of ALD $[113,114]$. Despite these limitations, the ALD-assisted modification of EENMs has demonstrated excellent photocatalytic activities in degrading organic pollutants and OCP and $\mathrm{PEC} \mathrm{H}_{2}$ evolution [26,115-117].

\subsection{Sol-Gel Chemistry}

The sol-gel method is a wet chemical deposition technique involving three main steps: (i) hydrolysis and partial condensation of a precursor by dip or spin coating; (ii) gel formation by polycondensation; and (iii) solvent evaporation and gel drying $[118,119]$. The sol-gel process can be used to fabricate films with high specific surface area and rich surface chemistry that allows for functionalization under low synthesis temperature, controllable reaction conditions and simple equipment [120]. Nevertheless, thin films produced by this method have some drawbacks, including expensive production cost, limited thickness controllability and poor mechanical properties [121]. Despite these drawbacks, the sol-gel method has been extensively used to tune the surface chemistry of the nanoporous materials. 
For instance, sol-gel derived synthesized coatings based on $\mathrm{TiO}_{2}$ and $\mathrm{WO}_{3}$ have been used to modify the inner surface of NAA-based structures to attain photocatalytic activity to effectively photodegrade organic pollutants under UV or visible light irradiation [22-25,122].

\subsection{Decoration with Nanoparticles}

The inner and/or outer surfaces of nanoporous materials are often decorated with metal-, semiconductor- and polymer-based nanoparticles to improve their photocatalytic properties by: (i) heterojunction formation and sensitization to change surface band bending (metal clusters or other semiconductors), (ii) suitable surface mediators for enhanced charge carrier transfer (co-catalytic effects), and (iii) LSPR effects for electromagnetic field enhancements around metal nanoparticles to achieve efficient light-harvesting properties [37].

The surface of EENMs can be decorated with noble metal nanoparticles (i.e., $\mathrm{Au}, \mathrm{Ag}, \mathrm{Pt}, \mathrm{Pd}$ and mixtures) by PVD [21,89,123,124], photoreduction method [36] or chemical reduction techniques [125]. This approach makes it possible to achieve co-catalytic effects to enhance photocatalytic reactions such as OCP or PEC $\mathrm{H}_{2}$ evolution and degradation of pollutants. Furthermore, EENMs can also be decorated with noble metal particles by anodization of low concentrations of valve metal-noble metal alloys $[20,29,124]$. This method provides a controllable distribution of particles over the surfaces of the EENMs with very uniform and defined particle diameters for efficient photocatalysis. Lee et al. demonstrated the in-situ formation of $\mathrm{Au}$ nanoclusters on $\mathrm{TiO}_{2}$ nanotubes grown by anodizing $\mathrm{Ti}-\mathrm{Au}$ alloys (Figure 3c) [20]. The homogeneous distribution of Au clusters with a typical particle size of $\sim 5-7 \mathrm{~nm}$ was achieved. Cluster spacing can be controlled by the Au concentration within the alloy and the anodization time. The remarkable enhancement in $\mathrm{H}_{2}$ evolution from ethanol solution was achieved by these noble metal-decorated $\mathrm{TiO}_{2}$ nanotubular structures, with an $\mathrm{H}_{2}$ production rate $\sim 30$ times faster than that of bare $\mathrm{TiO}_{2}$ nanotubes and $\sim 50$ times more efficient than compact (flat) $\mathrm{TiO}_{2}$ films decorated with the same number of Au clusters. Although Pt-decorated $\mathrm{TiO}_{2}$ nanotubes can be produced by anodization of Ti-Pt alloys, poor photocatalytic $\mathrm{H}_{2}$ generation was obtained due to the poisoning effect [20]. However, this study demonstrated that this decoration technique can be readily transferrable to other noble metals and alloys.

High photocatalytic rates have also been reported for EENMs decorated with semiconductor nanoparticles (i.e., $\mathrm{CuO}, \mathrm{Fe}_{2} \mathrm{O}_{3}, \mathrm{ZnO}, \mathrm{Bi}_{2} \mathrm{O}_{3}, \mathrm{ZnTe}$ or $\mathrm{NiO}$ ). These hybrid structures were produced by slow hydrolysis of precursors [126], dip coating [127], chemical vapor deposition [128] and electrodeposition $[30,109,110,129]$. Enhanced photocatalytic performances were attributed to heterojunction formation, increase in surface area and/or possible charge injection from the electronic states of decorated nanoparticles. Nevertheless, careful considerations on the long-term stability of these composite nanoporous materials are required since some of these materials are susceptible to electrolytic corrosion, photo corrosion and instability under an applied voltage. Other common narrow bandgap semiconductors such as $\mathrm{Bi}_{2} \mathrm{~S}_{3}, \mathrm{PbS}, \mathrm{ZnS}, \mathrm{CdS}$ and $\mathrm{CdSe}$ in the form of various nanostructures (i.e., nanoparticles, nanoclusters or quantum dots) can also be deposited on the inner surface of EENMs by successive ionic layer adsorption and reaction (SILAR) [130-132] as well as electrodeposition $[31,131,133]$ methods. These composite photocatalyst materials provide enhanced photocatalytic and photo-electrocatalytic performances. More recent works have decorated EENMs with C60 [134], graphene [135], Ag/AgCl [136], AgBr [137] and BiOI [138] for enhanced photocatalysis. These studies demonstrate that photocatalytic enhancements in these composite photocatalyst materials are associated with different effects such as redox capability of Ag halogenides, effective charge transportation of $\mathrm{C} 60$ or graphene, or strong visible light absorption of BiOI. Note, not only inorganic compounds but also organic monolayers such as silanes and phosphonates deposited on the surfaces of EENMs have been investigated for photocatalytic applications [37]. 


\section{Structural Engineering of Nanoporous Materials}

In 1987, Yablonovitch and John demonstrated the concept of photonic crystals (PCs), which are multi-dimensional periodically structured materials that can control the propagation of electromagnetic waves across their structure $[139,140]$. Since these pioneering studies, many theoretical concepts and technological applications of PCs in the field of sensing [141-150], photocatalysis [22-25,34-36,38-43] and dye-sensitized solar cells [151-153] have been demonstrated. PCs feature regularly distributed variations of dielectric constant, and thus the refractive index, in a 1D, 2D or 3D fashion [45]. PCs feature a characteristic photonic stopband (PSB) which corresponds to a wavelength range within which incoming photons are not allowed to propagate through the PC's structure. This light-matter interaction can be tailor-made engineered by the geometric features and chemical composition of the PC structures, enabling different forms of light control such as Bragg diffraction, multiple scattering, light confinement and slow photon (SP) effect. This approach provides new opportunities to enhance light-dielectric interactions for photocatalysis by confining, controlling and manipulating the propagation of incident photons of specific energies or wavelengths $[139,154,155]$.

Bragg diffraction forbids the propagation of photons within the PSB wavelength range, while multiple scattering increases trapping of photons propagating at wavelengths that are away from the PC's PSB. The SP effect slows down the group velocity of photons at the frequency edges of the PSBs. SPs generated on the red and blue edges of the PSB are primarily localized in the high and low dielectric parts of the PCs, respectively, increasing the lifetime of photons and the overall light absorption of the PC structure at specific spectral regions. In general, PC structures can be mechanistically described as an optical effective medium, in which the macroscopic optical properties of the composite PCs can be represented by model approximations such as Bruggeman, Drude, Looyenga-Landau-Lifshiftz, Lorentz-Lorenz and Maxwell Garnett [45]. For instance, the macroscopic optical properties of the composite NAA-PCs (i.e., air and alumina) can be estimated by averaging the properties of individual components (i.e., effective refractive index, effective dielectric constant) through effective medium approximation. In recent years, advances in nanofabrication technology have made it possible to develop conceptual PC structures. The most widespread techniques used to synthesize PCs are lithography and dry etching, vertical selective oxidation, wet chemical etching, fibre-pulling, embossing, self-organization and anodization [156]. Of all nanofabrication approaches, anodization has been demonstrated as a suitable method to fabricate EENM-based multi-dimensional PC structures with finely engineered geometric and optical properties. These PCs provide large surface area, versatility, scalable production, high throughput and resolution, making them attractive platform materials for a broad range of light-based technologies. However, the fabrication of EENMs by anodization still faces challenges. For instance, anodization of valve metals such as $\mathrm{Fe}, \mathrm{Zr}, \mathrm{W}, \mathrm{Nb}$, $\mathrm{Hf}, \mathrm{V}$ and $\mathrm{Co}$ are limited to straight nanotubular structures produced under constant potential and Fcontaining electrolytes [16,157].

Recent developments in anodization technology have demonstrated approaches to overcome these constraints, enabling the production of a plethora of PC structures through rationally designed anodization conditions to effectively translate electric field variations into in-depth porosity modulations. NAA produced by anodization of aluminium is the most researched EENM in the development of PC structures. Forms of NAA-PC structures include Fabry-Pérot interferometers (NAA-FPIs) [141-143], distributed Bragg reflectors (NAA-DBRs) [144-146], gradient index filters (NAA-GIFs) [147-149], optical microcavities (NAA- $\mu$ CVs) [158-160], apodized DBRs and GIFs (Apo-NAA-DBRs and Apo-NAA-GIFs) [161-163], bandpass filters (NAA-BPFs) [164] and linear variable bandpass filters (NAA-LVBPFs) [165]. The architecture and geometric features of NAA-PCs can be engineered with precision by pulse-like anodization under mild anodization conditions (i.e., low anodization voltage/current density and moderate acid electrolyte temperatures). Rationally designed anodization profiles along with optimal anodization conditions (i.e., the level of anodizing current density/voltage, type, concentration and temperature of acidic electrolyte) allow for engineering the effective medium of NAA in-depth during anodization. For instance, NAA-FPIs feature straight cylindrical nanopores 
with a homogeneous distribution of effective refractive index in-depth and are produced by constant voltage/current density anodization [141-143]. NAA-DBRs feature a stepwise distribution of effective refractive index between low and high values, which can be generated by stepwise pulse anodization (STPA) approach [144-146]. NAA-GIFs have a sinusoidal modulation of porosity and can be synthesized by sinusoidal pulse anodization (SPA) [147-149]. NAA- $\mu$ CVs are composed of a physical cavity layer sandwiched between two highly reflective mirrors, typically NAA-DBRs or NAA-GIFs, which can also be produced by different anodization approaches [158-160]. Several studies have successfully demonstrated the application of apodization functions to anodization profiles by modifying the anodization amplitude throughout time to produce apodized NAA-DBRs and NAA-GIFs [161-163].

NAA-BPFs can be produced by pseudo-stepwise pulse anodization (PSPA). Such PC structures allow for the transmission of light at certain bands of wavelengths in a selective manner while forbidding the propagation of photons of certain energies [164]. NAA-LVBPFs can be produced by the combination of SPA and selective chemical etching, where the effective medium of these EENM-based PC structures is engineered perpendicularly to the nanopores' growth direction [165]. Some detailed review articles describing the fundamental concepts, representative examples and realization of NAA-PCs are provided in $[45,70]$.

$\mathrm{TiO}_{2}$ nanotubes are the most representative example of $\mathrm{TiO}_{2}$-based $\mathrm{PCs}$, which are composed of self-ordered straight arrays of nanotubes. Distinct $\mathrm{TiO}_{2}-\mathrm{PC}$ morphologies have also been fabricated by manipulating the anodization voltage or water content in the electrolyte, including hierarchical nanotubes [34-36,151], periodically structured nanotubes $[46,150,152,164,165]$, bilayered nanotubes [153] and aperiodically structured nanotubes [166]. Hierarchical nanotubes with PC properties can be fabricated by manipulating the anodization voltage through sequential anodization steps [34-36]. The morphology of hierarchical top and bottom layers of $\mathrm{TiO}_{2}$ nanotubes can be finely tuned between nanoring/nanotube, nanopore/nanotube and nanohole-nanocave/nanotube morphologies.

$3 \mathrm{D}$ periodically structured $\mathrm{TiO}_{2}$ nanotubes with broadband omnidirectional photonic stopbands can be prepared by periodic current pulse anodization, where the currents are alternated between high and low current density values $[46,150,152,164,165]$. A bilayered $\mathrm{TiO}_{2} \mathrm{PC}$ structure featuring dense arrays of smooth-walled nanotubes and a periodic structure along axial direction can be obtained by periodic current pulse anodization followed by heat treatment and a single constant current anodization step [153]. Aperiodic $\mathrm{TiO}_{2}$ nanotube PCs with a gradually decreasing lattice constant (in an arithmetic sequence) can be synthesized by time-decreasing current density pulse anodization [166]. These $\mathrm{TiO}_{2}$ PCs have demonstrated their applicability in a variety of applications, including sensing [150], photonics [46,164,165], dye-sensitized solar cells [151-153], photovoltaics [166] and PEC $\mathrm{H}_{2}$ evolution [34-36], to name a few. Some excellent review articles introducing fundamental concepts and realization of $\mathrm{TiO}_{2}$ nanotube structures are provided in $[16,37,69]$.

Figure 4 shows schematic illustrations of representative NAA- and $\mathrm{TiO}_{2}$-based PCs fabricated by anodization of aluminium and titanium substrates, including SEM images, anodization profiles and characteristic PSBs of these EENM-based PC materials. Figure 4a presents schematics of various nanostructures of EENM-based PC including (i) NAA in the form of NAA-DBRs, NAA-GIFs and NAA- $\mu C V$ s, and (ii) $\mathrm{TiO}_{2}$ in the form of bilayer $\mathrm{TiO}_{2}-\mathrm{PCs}$, aperiodic $\mathrm{TiO}_{2}-\mathrm{PCs}$ and periodic $\mathrm{TiO}_{2}-\mathrm{PCs}$. Figure $4 \mathrm{~b}$ presents the geometric and optical features as well as the anodization profile employed to fabricate (i) NAA- $\mu \mathrm{CV}$ s and (ii) periodic $\mathrm{TiO}_{2}$-PCs. NAA- $\mu$ CVs composed of a physical cavity layer sandwiched between two highly reflective mirrors (i.e., NAA-GIFs) were fabricated by sinusoidal pulse anodization and feature a resonance band within the characteristic PSB (Figure $4 \mathrm{~b}(\mathrm{i})$ )). Periodic $\mathrm{TiO}_{2}$-PCs featuring small voids around each stack interface and broad PSBs over the entire visible spectrum were obtained under current pulse anodization (Figure $4 b(i i)$ ).

Although anodization of valve metals such as $\mathrm{Fe}, \mathrm{Zr}, \mathrm{W}, \mathrm{Nb}, \mathrm{Hf}, \mathrm{V}$ and $\mathrm{Co}$ has been demonstrated successfully, the production of PC structures based on the anodic oxides of these valve metals remains challenging $[16,57,60-68,157]$. The development of advanced PC structures with precisely controlled 
optical properties is still limited. Therefore, future developments in anodization of these valve metals to fabricate PCs will be essential to spread the applicability of EENMs across many technological disciplines, including photocatalysis and photovoltaics.

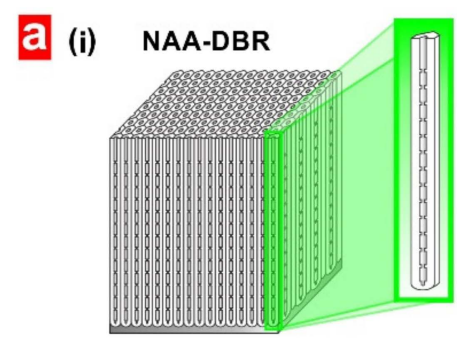

(ii)

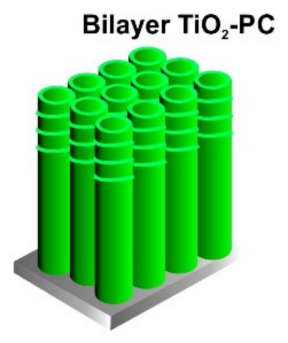

b (i)

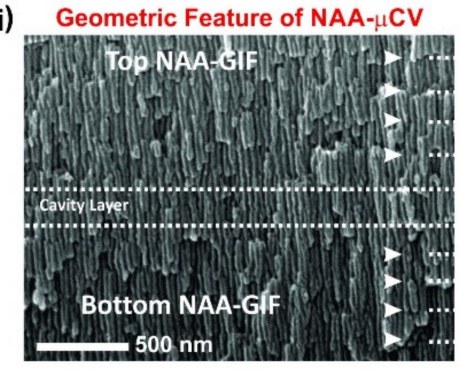

(ii) Geometric Feature of Periodic $\mathrm{TiO}_{2}-\mathrm{PC}$

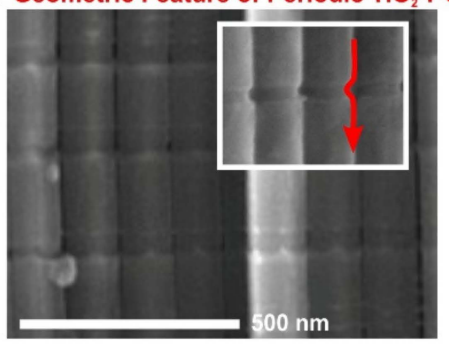

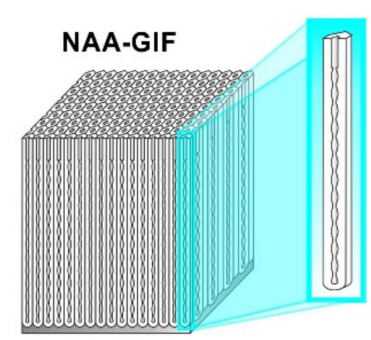
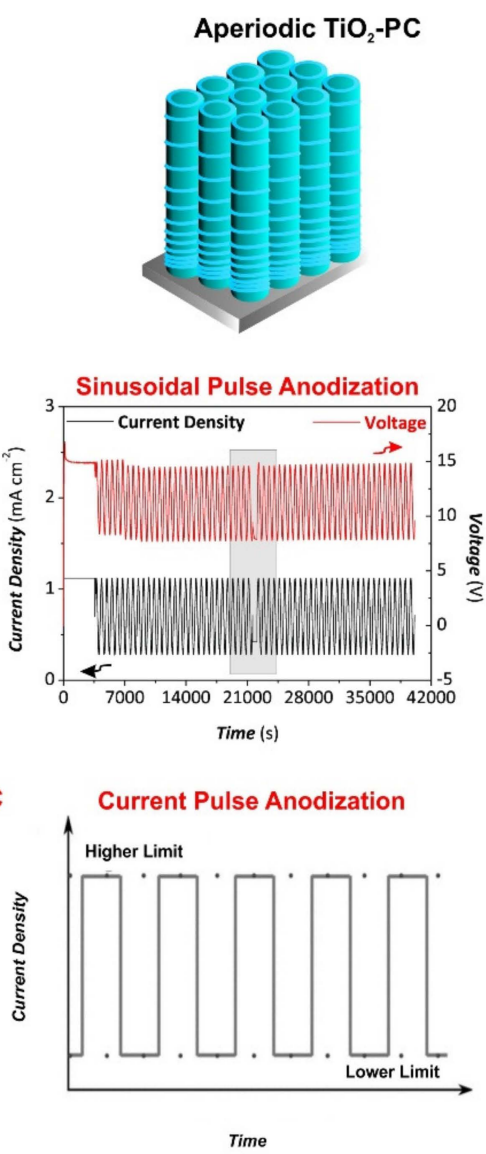
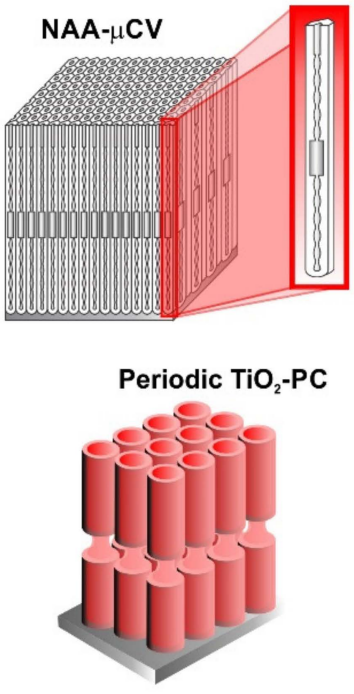

Optical Feature of NAA- $\mu$ CV

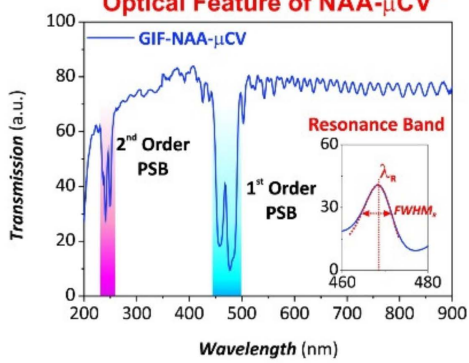

Optical Feature of Periodic $\mathrm{TiO}_{2}-\mathrm{PC}$

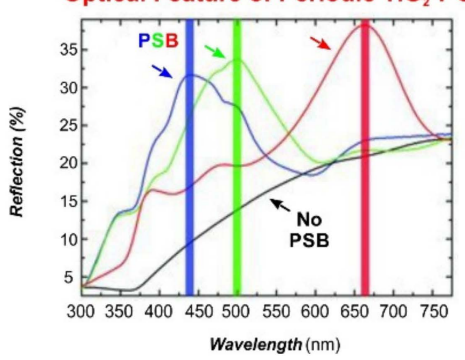

Figure 4. Structural engineering of electrochemically engineered nanoporous materials (EENMs) by anodization. (a) Schematics showing examples of (i) nanoporous anodic alumina photonic crystals (NAA-PCs) (i.e., NAA-DBR-NAA distributed Bragg reflector; NAA-GIF-NAA gradient-index filter; NAA- $\mu$ CV-NAA optical microcavity), and (ii) $\mathrm{TiO}_{2}$ photonic crystals $\left(\mathrm{TiO}_{2}\right.$-PCs) (i.e., bilayer, aperiodic and periodic). (b) Representative SEM images (left), anodization profile (center) and photonic stopbands (PSBs) (right) of (i) NAA- $\mu \mathrm{CV}$ and (ii) periodic $\mathrm{TiO}_{2}$-PCs. Reproduced from [160], with copyright permission from the Royal Society of Chemistry, 2018, and [164], with copyright permission from Wiley-VCH Verlag GmbH \& Co. KGaA, Weinheim, 2011, respectively.

\section{Electrochemically Engineered Nanoporous Materials for Photocatalysis}

EENMs have been devised as platform materials for photocatalysis due to their unique physical, chemical, electrical and optical properties. EENMs can be used under open-circuit conditions or as a photoanode together with an inert or catalytic cathode such as $\mathrm{Pt}, \mathrm{C}$ and others. The effective 
medium, surface chemistry and crystallinity of EENMs can be precisely engineered for enhanced photocatalytic applications, including open-circuit dye degradation, and OCP and $\mathrm{PEC} \mathrm{H}_{2}$ generation. In many cases, photocatalytic performances of EENMs are superior to those of benchmark photocatalyst nanoparticles due to different phenomena, including an increase in effective surface area, enhanced orthogonal carrier separation, the formation of electronic junctions and optimized geometry and crystallinity [37]. This section summarizes the most important factors affecting the photocatalytic activity of EENMs and gives a brief overview of current efforts towards EENM-based photocatalytic and photo-electrocatalytic systems.

\subsection{Key Factors Influencing Photocatalysis}

A common factor influencing the photocatalytic performance of EENMs is the crystal structure (i.e., polymorph and facets). EENMs fabricated by anodization are amorphous in nature but their crystalline structure can be modified by post-annealing treatment. Crystallinity affects the conductivity of the anodic oxide and lifetime of charge carriers in the structure of the photocatalyst material. For instance, annealing $\mathrm{TiO}_{2}$ nanotube structures in air with increasing annealing temperature $>300{ }^{\circ} \mathrm{C}$ results in better photocatalytic activities due to the formation of anatase crystals and the higher crystallinity degree of $\mathrm{TiO}_{2}$ [18]. When $\mathrm{TiO}_{2}$ nanotubes are annealed at $650{ }^{\circ} \mathrm{C}$, anatase-rutile crystal junctions are formed, enhancing photocatalytic degradation of pollutants and OCP $\mathrm{H}_{2}$ evolution under solar light or UV laser illumination due to band offsets and increment in light absorption. However, careful control over annealing temperature and oxidizing conditions (i.e., in $\mathrm{O}_{2}$ ) is required since these conditions may deteriorate the nanostructures or lead to the formation of other crystal structures that might detrimentally affect photocatalytic performances [37]. Exposure of different crystal planes of crystalline structures also influences the photocatalytic activity of EENMs in photocatalysis due to the intrinsically different energetic nature between distinct planes and the formation of microjunctions. Lee et al. observed photocatalytic enhancements in anatase $\mathrm{TiO}_{2}$ nanotubes featuring predominantly highly energetic $\{001\}$ facets (i.e., TNT-11 fabricated at an anodization time of $11 \mathrm{~h}$ ) using the photocatalytic degradation of Rhodamine B as an indicator [19]. Enhancements were attributed to these high energetic facets, which provide sites to boost the production of active oxygen species such as $\cdot \mathrm{OH}, \cdot \mathrm{O}_{2}{ }^{-}$and $\mathrm{H}_{2} \mathrm{O}_{2}$ upon UV irradiation (Figure 5a).

The structural features of EENMs play a key role in enhancing photocatalysis. In general, a strong increase in photocatalytic degradation kinetics of organic pollutants can be observed with increasing nanopore length, which is attributed to an enhanced light absorption efficiency and a specific surface area increase (Figure 5b) [18,22,37]. Other geometric features influencing the photocatalytic performance of EENMs are the nanopore/nanotube diameter, surface features and sidewall roughness [37]. EENMs in the form of PC structures provide other approaches to further enhance the utilization of light for further boosting photocatalytic or PEC reactions. [22-25,39-43]. The chemical structure of EENMs can be intrinsically or extrinsically modified to improve their photocatalytic performance by formation of heterojunctions to change surface band bending, creation of suitable surface states for efficient charge exchange, integration of co-catalytic effects for photocatalytic and PEC reactions, incorporation of LSPR effects to concentrate electromagnetic fields in the vicinity of metal particles for more efficient light-harvesting, and increasing specific surface area [37]. These phenomena are strongly dependent on the elements or materials incorporated into the structure of EENMs and the type of treatment applied. For instance, $\mathrm{OCP} \mathrm{H}_{2}$ evolution by $\mathrm{TiO}_{2}$ nanotubes can only be significantly enhanced with the presence of co-catalysts such as Pt nanoparticles and by exposure of the EENM to activating treatments such as $\mathrm{H}_{2}$-annealing and ion-implantation. On the other hand, the conductivity of $\mathrm{TiO}_{2}$ nanotubes can be adjusted to attain optimal PEC activities by doping their structure with visible-light transition metals (i.e., $\mathrm{Nb}, \mathrm{Ta}, \mathrm{Ru}$, etc.) or exposure to reductive treatments (Figure $5 \mathrm{c}$ ). 


\subsection{Non-Structurally Engineered Nanoporous Materials Produced by Anodization}

$\mathrm{TiO}_{2}$ nanotubes produced by anodization of Ti substrates have been extensively employed for photocatalysis, especially for the conversion of sunlight green energy $\left(\mathrm{H}_{2}\right.$ gas), photodegradation of harmful environmental organic pollutants, and photosynthesis organic compounds and photocatalytic-based biomedical applications. $\mathrm{TiO}_{2}$ is regarded as the benchmark photocatalytic material due to its low cost, high photostability, strong chemical resistance and excellent electronic properties $[16,37,69]$. Anodization of Ti substrates under specific conditions results in hexagonally ordered $\mathrm{TiO}_{2}$ nanotube arrays, which grow perpendicularly to the surface of the underlying Ti substrate. From a photocatalysis point-of-view, $\mathrm{TiO}_{2}$-based nanotubular structures provide several advantages, including an increase in specific surface area, efficient orthogonal charge carrier separation and formation of well-defined electronic gradients.

(i)

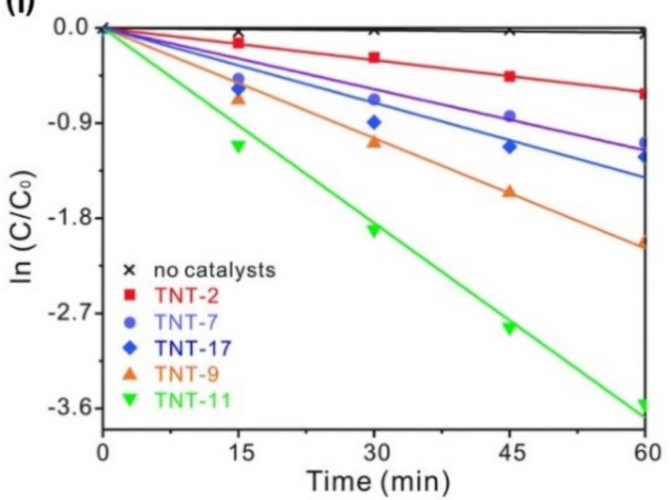

b

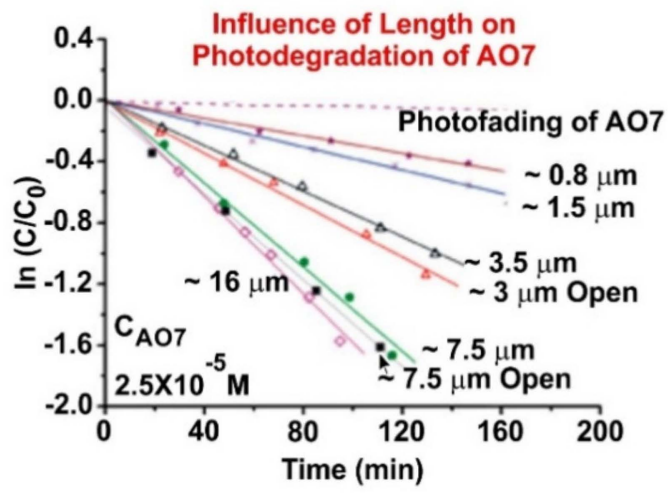

(ii)

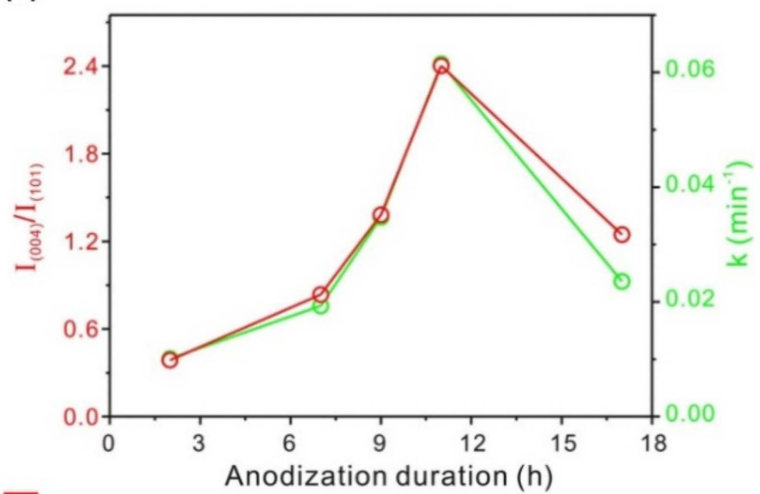

C

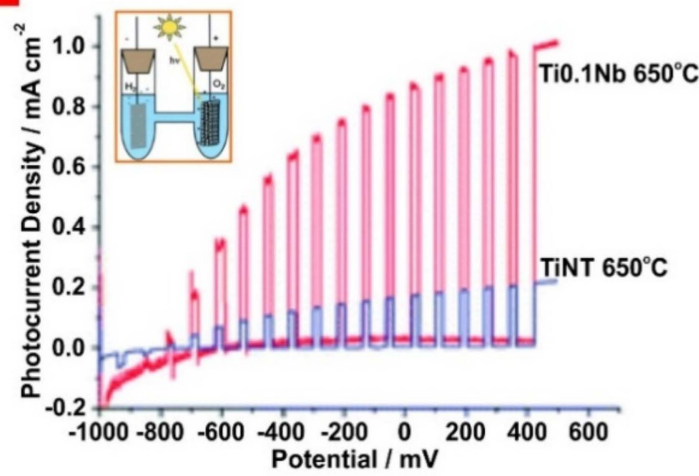

Figure 5. Examples of key factors that influence the photocatalytic activity of $\mathrm{TiO}_{2}$ nanotubes. (a) (i) Photocatalytic degradation kinetics for Rhodamine $\mathrm{B}$ by $\mathrm{TiO}_{2}$ nanotubes fabricated with different anodization time, and (ii) (red) (004/101) facets intensity ratios and (green) photocatalytic rate constants as a function of anodization time. Reproduced from [19], with copyright permission from the Royal Society of Chemistry (RSC) on behalf of the Centre National de la Recherche Scientifique and the RSC, 2016. (b) Influence of $\mathrm{TiO}_{2}$ nanotube layer thickness on the photocatalytic degradation of AO7. Reproduced from [37], with copyright permission from American Chemical Society, 2017. (c) Photocurrent transients as a function of applied potential for $\mathrm{TiO}_{2}$ and $\mathrm{Ti} 0.1 \mathrm{Nb}$ nanotubes annealed at $650{ }^{\circ} \mathrm{C}$ demonstrating the water splitting performance in $1 \mathrm{M} \mathrm{KOH}$ under AM 1.5 condition. Reproduced from [7], with copyright permission from the Royal Society of Chemistry, 2011.

Already pristine $\mathrm{TiO}_{2}$ nanotubes perform relatively fast photodegradation of various organic pollutants in water such as herbicides $[167,168]$, pharmaceutical compounds $[169,170]$, organochlorine compounds [171,172], cosmetic compounds [170] and azo or organic dyes [4,19]. Some of these processes have been assessed for real-life photocatalytic applications, using water matrices with 
three different common water constituents (i.e., bicarbonate ions, phosphate ions and natural organic matters) $[168,169]$. Similarly, pristine $\mathrm{TiO}_{2}$ nanotubes were shown to have excellent photocatalytic capabilities in the decomposition of gaseous volatile organic compounds such as acetylaldehyde [5], methane [6], hexane [27] and toluene [173]. Despite having demonstrated excellent photocatalytic performances in degrading organic pollutants in air and water, the average ratio of the efficacy of $\mathrm{TiO}_{2}$ over the benchmark photocatalyst form of $\mathrm{TiO}_{2}-\mathrm{P}_{2} 5 \mathrm{TiO}_{2}$ nanoparticles-was only $\sim 1$ and 1.5 for air and water, respectively [174]. Numerous studies have performed chemical modifications of as-produced $\mathrm{TiO}_{2}$ nanotubes, either intrinsically or extrinsically by anodization of alloy substrates $[84,85,89]$, doping $[33,76-79,91,94]$, reduction treatments [95,96], ALD [26,115,116], electrodeposition [110] and decoration with nanoparticles $[21,89,124-138]$. These $\mathrm{TiO}_{2}$-based nanotubular structures have shown superior photocatalytic activities over pristine $\mathrm{TiO}_{2}$ nanotubes for the degradation of various organic pollutants in water, particularly organic and azo dyes. For instance, Sopha et al. deposited uniform $\mathrm{TiO}_{2}$ coatings by ALD within $\mathrm{TiO}_{2}$ nanotube layers fabricated by anodization for photocatalysis (Figure 6a) [26]. An efficient charge carrier separation and high surface area were achieved for $\mathrm{TiO}_{2}$ nanotubes (i.e., the thickness of anodic film $\sim 5 \mu \mathrm{m}$ and a diameter of nanotubes $\sim 230 \mathrm{~nm}$ ), with an optimal ALD $\mathrm{TiO}_{2}$ coating thickness of $\sim 11 \mathrm{~nm}$.

The photocatalytic performance of $\mathrm{ALD} \mathrm{TiO}_{2}$ coated $\mathrm{TiO}_{2}$ nanotubes (i.e., TNT with 200 cycles of ALD) was also found to be superior to their uncoated or $\mathrm{TiO}_{2}$ nanoparticle-decorated counterparts by $72 \%$ and $88 \%$, respectively, in degrading methylene blue under $365 \mathrm{~nm}$ UV light illumination. $\mathrm{TiO}_{2}$ nanotubes modified with $\mathrm{P}, \mathrm{W}, \mathrm{Mn}, \mathrm{Pt}, \mathrm{TiO}_{2}, \mathrm{Bi}_{2} \mathrm{~S}_{3}$ and lanthanides by doping, anodization of alloy substrates, decoration with quantum dots and ALD have also shown successful photocatalytic degradation of gaseous pollutants (i.e., toluene, hexane) $[27,79,90,130,175]$ and the photoreduction of $\mathrm{Cr}^{6+}$ [176]. In many of these cases, doped $\mathrm{TiO}_{2}$ nanotubes achieved better photocatalytic performance than their pristine analogues. Despite the advantages of chemically modified $\mathrm{TiO}_{2}$ nanotubes for photocatalysis, the addition of coating onto $\mathrm{TiO}_{2}$ nanotubes may not necessarily have the same beneficial effect for the photocatalytic degradation of organic pollutants in air and water. For instance, Sopha et al. have reported that $\mathrm{ALD} \mathrm{TiO}_{2}$ coatings in $\mathrm{TiO}_{2}$ nanotube layers do not enhance the photocatalytic degradation of hexane in air due to a reduction of active surface area (Figure 6b) [27]. Several studies have explored the application of $\mathrm{TiO}_{2}$ nanotubes for photocatalytic conversion of $\mathrm{CO}_{2}$ into $\mathrm{CH}_{4}$ (in a wet gas phase) or $\mathrm{CH}_{3} \mathrm{OH}$ (in liquid $\mathrm{H}_{2} \mathrm{O}$ ) in the presence of $\mathrm{H}_{2} \mathrm{O}[177,178]$, including modified $\mathrm{TiO}_{2}$ nanotube crystal structures with dopants [9] and decoration with co-catalyst nanoparticles $[9,30,179]$ under UV, UV-visible and solar sunlight irradiation conditions.

For example, Varghese et al. developed $\mathrm{N}$-doped $\mathrm{TiO}_{2}$ nanotubes decorated with $\mathrm{Pt}$ and/or $\mathrm{Cu}$ co-catalyst nanoparticles to photo-reduce $\mathrm{CO}_{2}$ with $\mathrm{H}_{2} \mathrm{O}$ vapour under outdoor sunlight irradiation (Figure 6c) [9]. Strategies to enhance photocatalytic $\mathrm{CO}_{2}$ conversion rates in $\mathrm{TiO}_{2}$ nanotubular structures include (i) employing high specific surface area of $\mathrm{TiO}_{2}$ nanotubes with a wall thickness thin enough to facilitate efficient transportation of photogenerated charge carriers to surface species; (ii) introducing $\mathrm{N}$ dopants to modify $\mathrm{TiO}_{2}$ bandgap for absorbing and utilizing visible light; and (iii) distributing co-catalyst nanoparticles on nanotubes to efficiently adsorb reactants and aid redox reactions. Upon natural sunlight irradiation, a very high hydrocarbon production rate of $\sim 111 \mathrm{ppm} \mathrm{cm}^{-2} \mathrm{~h}^{-1}$ was achieved, which is at least 20 times higher than those reported for $\mathrm{Pt} / \mathrm{TiO}_{2}$ under UV illumination. Nevertheless, conversion of $\mathrm{CO}_{2}$ to useful fuels is still kinetically hindered by the energetically disadvantageous nature of the two electron transfer steps involved in the conversion process.

Chemically modified $\mathrm{TiO}_{2}$ nanotubes have also been widely investigated for their potential in photocatalytic $[20,28,29,97-99,103,117,123]$ and photo-electrocatalytic $[7,31,74,86-88,109]$ water splitting to generate clean $\mathrm{H}_{2}$. $\mathrm{TiO}_{2}$ nanotubes split water efficiently as photoanodes in a photo-electrochemical setting with an ideal electrode (such as $\mathrm{Pt}$ ) for "slow" cathodic $\mathrm{H}_{2}$ evolution reaction under voltage bias [179]. Photoanodes based on $\mathrm{TiO}_{2}$ nanotubes have been reported to be more promising than nanoparticulate layers due to their well-defined geometry and incorporation with co-catalysts (i.e., $\mathrm{CuO}$ and $\mathrm{NiO}$ ) [31,109] or dopants (i.e., $\mathrm{Nb}, \mathrm{Ru}, \mathrm{C}$ and $\mathrm{Ta}$ ) $[7,74,86-88]$. Particularly 
promising results regarding the modification of $\mathrm{TiO}_{2}$ nanotubes for water splitting have been reported by Roy et al. [87] and Yoo et al [88]. $\mathrm{TiO}_{2}$ nanotubes were synthesized by anodizing low concentration Ti-Ru alloys, where $\mathrm{Ru}$ in $\mathrm{TiO}_{2}$ can either act as a dopant for PEC water splitting or be present as $\mathrm{RuO}_{2}$ to act as a co-catalyst for $\mathrm{O}_{2}$ evolution. In PEC experiments, Roy et al. successfully demonstrated very high light-to- $\mathrm{H}_{2}$ conversion efficiencies of an almost six-fold increase for intrinsically $\mathrm{Ru}$-doped $\mathrm{TiO}_{2}$ nanotubes in comparison with undoped $\mathrm{TiO}_{2}$ nanotubes in terms of photocurrent density (Figure 6d) [89]. While $\mathrm{TiO}_{2}$ can be used as a platform material to perform the photocatalytic synthesis of organics, the high selectivity required for organic synthesis is often not reached due to the non-selective character of generated free radicals (e.g., $\cdot \mathrm{OH}$ radicals) upon light irradiation [37]. However, modification of the electronic properties and nanoporous geometry of $\mathrm{TiO}_{2}$ can steer carrier energies and lifetimes to overcome this inherent constraint $[13,14]$. Recently, Tripathy et al. demonstrated modification of crystal structures (i.e., anatase or rutile) and/or incorporation of $\mathrm{Ru}$ dopant into $\mathrm{TiO}_{2}$ nanotubes for photocatalytic oxidation of toluene under $325 \mathrm{~nm}$ UV light illumination (Figure 6e) [13]. A significant change in the main reaction product (i.e., benzoic acid versus benzaldehyde) can be achieved, where certain undesired reaction pathways can be completely shut down due to the change in the electronic properties by Ru doping. Ru states prevent the formation of intermediate superoxide radicals, switching the reaction product from toluene to benzoic acid. The geometric features of $\mathrm{TiO}_{2}$ nanotubes also show higher selectivity than that of nanoparticle-based layers, indicating that the combination of nanoarchitecture and tailor-engineered electronic bands of photocatalyst materials are a promising approach for achieving high selectivity in organic synthesis.

Nanotubular $\mathrm{TiO}_{2}$ structures also provide new opportunities to induce chain scission in functional organic monolayers (i.e., silanes and phosphonates) for drug delivery applications [180-182]. When exposed to UV light, scission of organic chains occurs on anchoring groups, leaving the inorganic section of these molecules attached to the surface of $\mathrm{TiO}_{2}$ nanotubes. As-produced and $\mathrm{Fe}_{3} \mathrm{O}_{4}$ nanoparticle-decorated $\mathrm{TiO}_{2}$ nanotubes have also shown potential for photocatalytic killing of cancer cells under UV light irradiation [182,183]. Faraji et al. have shown that $\mathrm{TiO}_{2}$ nanotubes modified with $\mathrm{Ag} /$ Benzene have effective sterilization effects by degrading a resilient bacterium such as Escherichia coli (E. coli) under UV and visible light irradiation due to LSPR effect and efficient charge separation (Figure 6f) [184].

Other pristine and chemically modified oxide nanotubes such as $\mathrm{ZrO}_{2}[185], \mathrm{WO}_{3}[186,187]$ and $\mathrm{Co}_{3} \mathrm{O}_{4}$ [68] have also been investigated for various photocatalytic and photo-electrocatalytic applications, including degradation of organic pollutants, water splitting and $\mathrm{CO}_{2}$ reduction, due to their favorable band-edge positions, superior chemical stability, and low cost. Although NAA is an electronic insulator with a wide energy bandgap (i.e., 8.0-9.5 eV), the inner surface of this EENM can be modified with semiconductor materials for photocatalysis. Several studies have demonstrated successful photocatalytic applications of semiconductor-modified NAA-based platforms, including $\mathrm{CO}_{2}$ reduction [10] and photodegradation of organic pollutants [122,188]. 


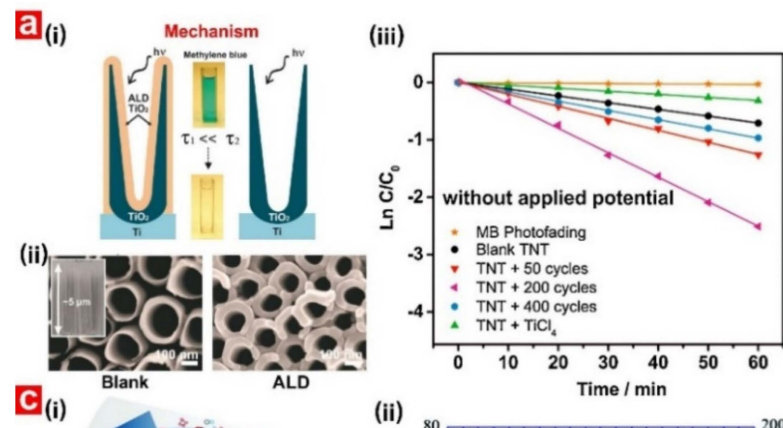

b
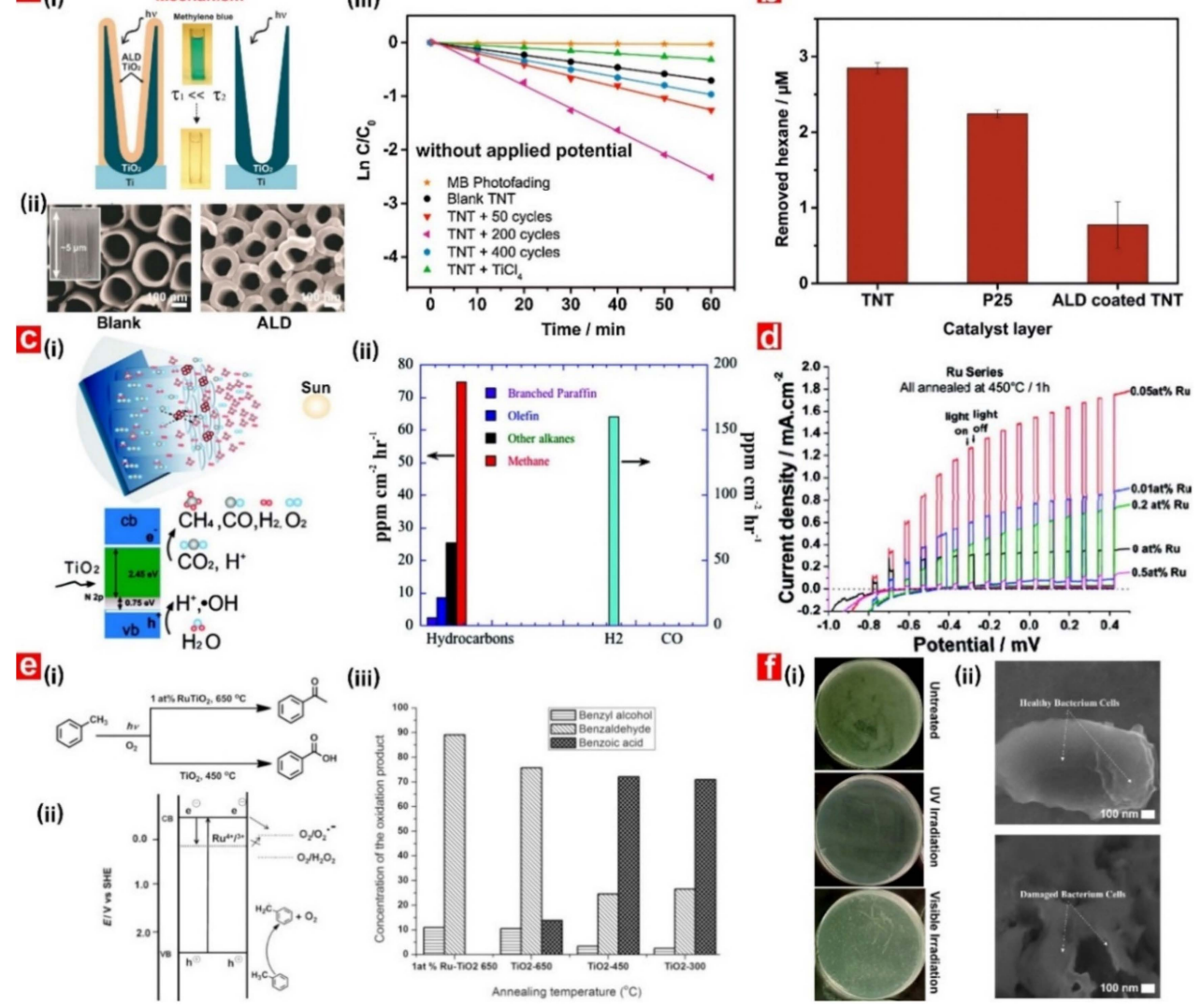

(iii)
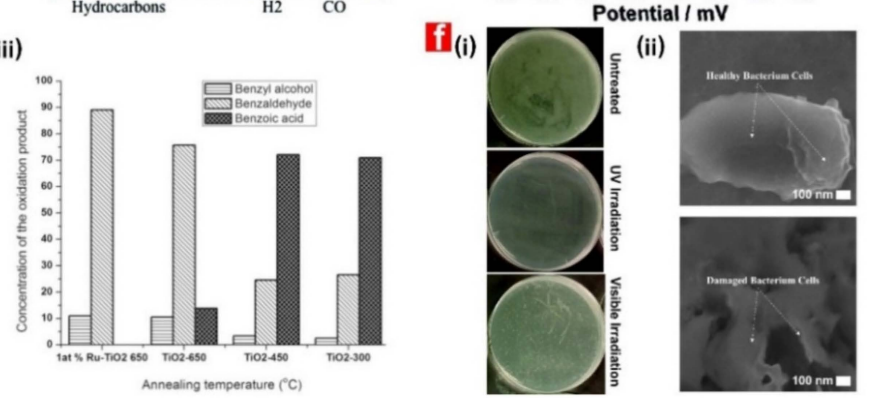

Figure 6. Applicability of non-structural electrochemical engineered nanoporous materials (EENMs) in photocatalytic and photoelectrochemical applications. (a) (i) Photocatalytic degradation mechanism for methylene blue by $\mathrm{TiO}_{2}$ nanotubes coated with $\mathrm{TiO}_{2}$ layers via ALD; (ii) SEM images of pristine and $\mathrm{ALD} \mathrm{TiO} \mathrm{O}_{2}$ coated $\mathrm{TiO}_{2}$ nanotubes; and (iii) photocatalytic degradation rates of $\mathrm{MB}$ for blank, ALD $\mathrm{TiO}_{2}$ coated $\mathrm{TiO}_{2}$ nanotubes (50, 200 and 400 cycles) and $\mathrm{TiO}_{2}$ nanoparticle-decorated $\mathrm{TiO}_{2}$ nanotubes $\left(\mathrm{TiCl}_{4}\right)$ under UV light illumination. Reproduced from [26], with copyright permission from Elsevier Ltd., 2017. (b) Photocatalytic removal of hexane in air for three different $\mathrm{TiO}_{2}$-based photocatalysts under UV light illumination. Reproduced from [27], with copyright permission from Elsevier B.V., 2018. (c) (i) Schematic illustration of sunlight-driven photocatalytic $\mathrm{CO}_{2}$ reduction using $\mathrm{N}$-doped $\mathrm{TiO}_{2}$ nanotubes surface-loaded with $\mathrm{Cu}$ and/or Pt co-catalyst nanoparticles; (ii) Product evolution rates from $\mathrm{N}$-doped $\mathrm{TiO}_{2}$ nanotubes annealed at $600{ }^{\circ} \mathrm{C}$ and surface loaded with $52 \% \mathrm{Cu}$ and $48 \% \mathrm{Pt}$ nanoparticles. Reproduced from [9], with copyright permission from American Chemical Society, 2009. (d) Photo-electrochemical water splitting: photocurrent transient vs. potential curves in $1 \mathrm{M} \mathrm{KOH}$ solution using an $\mathrm{Ag} / \mathrm{AgCl}$ reference electrode under $\mathrm{AM} 1.5$ illumination for different Ru substrate contents $(0 \%-1.2 \%) \mathrm{TiO}_{2}$ nanotubes annealed at $450{ }^{\circ} \mathrm{C}$ for $1 \mathrm{~h}$. Reproduced from [87], with copyright permission from American Chemical Society, 2011. (e) Tuning reaction selectivity: (i) illustration of different photocatalytic pathways on $\mathrm{TiO}_{2}$ nanotubes, (ii) illustration of the band position during toluene oxidation on pristine and $\mathrm{Ru}$-doped $\mathrm{TiO}_{2}$ nanotubes under $\mathrm{UV}$ irradiation; and (iii) product distribution from the oxidation of toluene after $4 \mathrm{~h} \mathrm{UV}$ exposure of pristine and Ru-doped $\mathrm{TiO}_{2}$ nanotubes. Reproduced from [13], with copyright permission from Wiley-VCH Verlag GmbH \& Co. KGaA, Weinheim, 2014. (f) (i) Digital images of bacteria colony counting (dilution: 10-4) showing the antibacterial activity of $\mathrm{Ag} /$ benzene modified $\mathrm{TiO}_{2}$ nanotubes in different irradiation conditions after $1 \mathrm{~h}$; and (ii) SEM images of bacteria cell before (top) and after (bottom) exposure to Ag/benzene modified $\mathrm{TiO}_{2}$ nanotubes under visible light irradiation. Reproduced from [184], with copyright permission from the Royal Society of Chemistry (RSC) on behalf of the Centre National de la Recherche Scientifique and the RSC, 2018. 


\subsection{Structurally Engineered Nanoporous Materials Produced by Anodization}

Although various structurally engineered forms of $\mathrm{TiO}_{2}-\mathrm{PCs}$ have been synthesized by anodization [34-36,46,150-153,164-166], only pristine and noble metal (i.e., Ag or Au) decorated hierarchical nanotubes have been investigated for clean $\mathrm{H}_{2}$ energy generation via PEC water splitting [34-36]. Zhang et al. developed hierarchical $\mathrm{TiO}_{2}$ nanotubes by varying the voltage during a two-step constant anodization for PEC water splitting (Figure 7a) [34]. Hierarchical $\mathrm{TiO}_{2}$ nanotube arrays were composed of a periodically organized nanoporous layer on top of a uniform nanotube array, in which the top nanoporous structure served as a PC to enhance optical absorption of the overall photocatalyst platform. Of all the hierarchical $\mathrm{TiO}_{2}$ structures assessed in this study (i.e., nanoring (top)/nanotube (bottom), nanopore (top)/nanotube (bottom) and nanohole-nanocave (top)/nanotube (bottom)), the nanopore (top)/nanotube (bottom) configuration achieved the highest photocurrent density value (i.e., $1.59 \mathrm{~mA} \mathrm{~cm}^{-2}$ at $1.23 \mathrm{~V}$ vs RHE) under $\mathrm{AM} 1.5 \mathrm{G}$ illumination. Lian et al. prepared Ag quantum dots-modified hierarchical $\mathrm{TiO}_{2}$ nanostructures (i.e., nanoring (top)/nanotube (bottom)) utilizing a similar fabrication method for $\mathrm{PEC}_{2}$ evolution under visible light irradiation [35]. A high photocatalytic $\mathrm{H}_{2}$ evolution rate (i.e., $124.5 \mu \mathrm{mol} \mathrm{cm}^{-2} \mathrm{~h}^{-1}$ ) was achieved, which was attributed to synergetic effects of $\mathrm{Ag}$ and the hierarchical PC structure. This smart design makes it possible to harness strong LSPR effect and anti-shielding effect of ultrafine Ag quantum dots within the same photocatalyst platform (Figure $7 \mathrm{~b}$ ).

Zhang et al. developed $\mathrm{TiO}_{2}$ nanotube-based PCs by voltage variation during the second anodization step flowing a stepwise profile between high and low voltage to compensate for the loss of electric field intensity [36]. This fabrication approach improves periodicity and uniformity of the nanoporous top layer of hierarchical $\mathrm{TiO}_{2}$ nanostructures, which are critical factors for the formation of an effective PC structure with well-resolved photonic stopband (PSB). Nanoring (top)/nanotube (bottom) hierarchical $\mathrm{TiO}_{2}$ structures feature well-defined PSBs, which can be finely tuned across high-irradiance spectral regions for enhanced photocatalytic and PEC performances [34]. 
a (i)

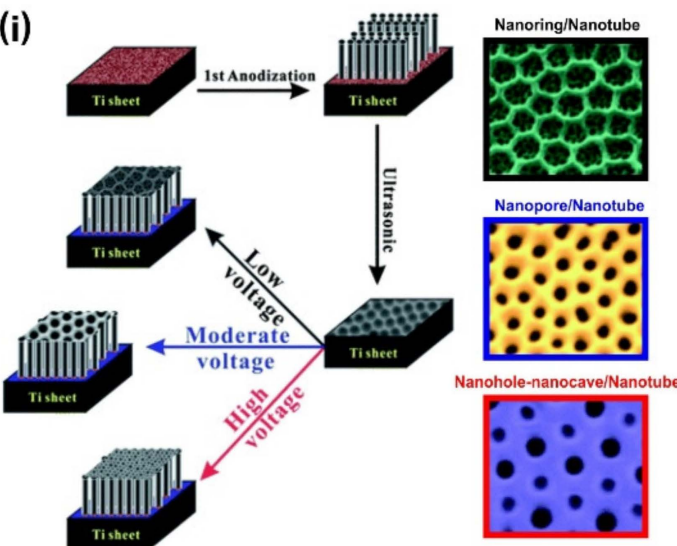

b (i)

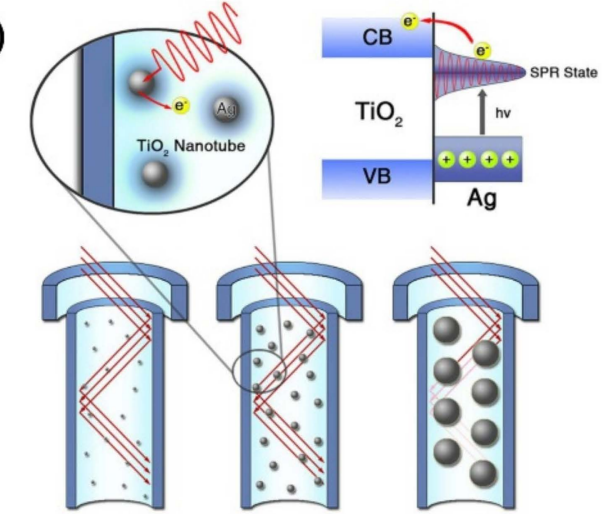

C (i)

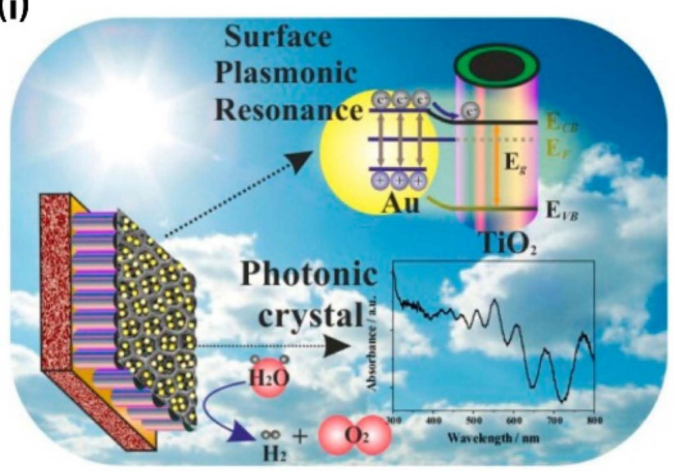

(ii)

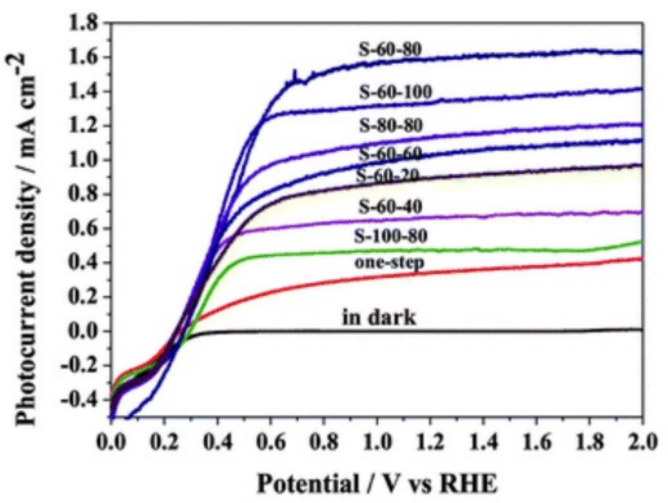

(ii)

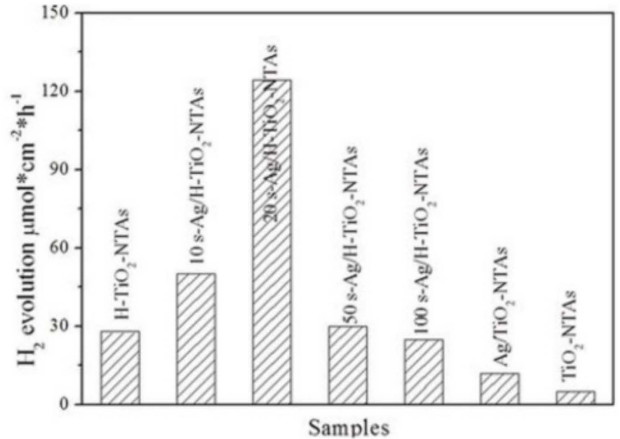

(ii)

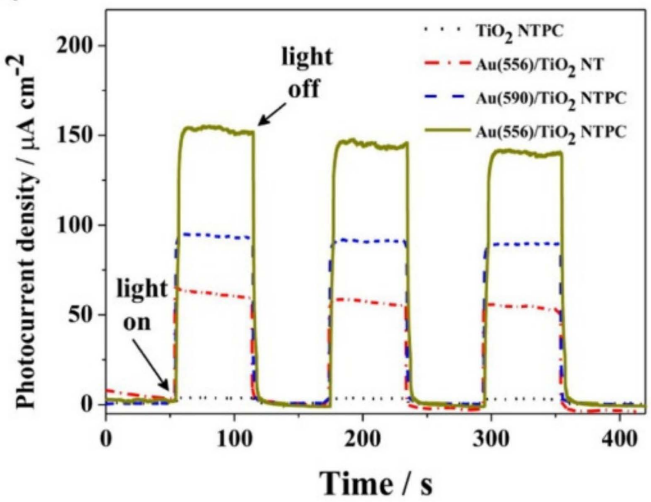

Figure 7. Examples of applicability of pristine and noble metal-decorated hierarchical $\mathrm{TiO}_{2}-\mathrm{PCs}$ in photoelectrochemical (PEC) $\mathrm{H}_{2}$ evolution. (a) (i) Two-step anodization process (left) and SEM images of various top layer nanostructures (right) of hierarchical $\mathrm{TiO}_{2}-\mathrm{PCs}$, and (ii) $\mathrm{PEC}$ water splitting performances in terms of linear-sweep voltammograms collected with a scan rate of $5 \mathrm{mV} \mathrm{s}^{-1}$ in dark and under illumination for various hierarchical $\mathrm{TiO}_{2}-\mathrm{PCs}$. Reproduced from [34], with copyright permission from the Royal Society of Chemistry, 2012. (b) (i) Light penetration mechanism in Ag nanocrystal-loaded hierarchical $\mathrm{TiO}_{2}-\mathrm{PCs}$, and (ii) $\mathrm{PEC} \mathrm{H}_{2}$ production rate by various $\mathrm{TiO}_{2}$-based photocatalyst platforms under visible light irradiation. Reproduced from [35], with copyright permission from Scientific Reports, 2015. (c) (i) Summary of Au-decorated hierarchical $\mathrm{TiO}_{2}-\mathrm{PCs}$ for PEC water splitting, and (ii) amperometric I-t curve at an applied potential of $1.23 \mathrm{~V}$ vs RHE under visible light illumination with $60 \mathrm{~s}$ light on/off cycles. Reproduced from [36], with copyright permission from American Chemical Society, 2013.

Furthermore, Zhang et al. assembled $20 \mathrm{~nm}$ Au nanocrystals onto these PC structures and achieved a photocurrent density of $\sim 150 \mu \mathrm{A} \mathrm{cm}^{-2}$ at $1.23 \mathrm{~V}$ vs RHE, which is the highest value reported to date in 
hybrid plasmonic $\mathrm{Au} / \mathrm{TiO}_{2}$ system for $\mathrm{PEC}$ water splitting under visible light irradiation (Figure 7c) [36]. This significant enhancement was ascribed to match the SPR absorption to the PSB of the PC structure, where the PC structure can localize, trap and provide multiple passes for plasmonically active photons generated around the Au nanocrystals. Thus, the average photon path length is increased and results in an enhanced SPR intensity of the Au nanocrystals for efficient PEC water splitting.

Despite providing outstanding light-harvesting capabilities, NAA-based PC structures produced by anodization of aluminium cannot be used for photocatalysis applications due to the high energy bandgap of alumina. However, recent studies have demonstrated promising results in the development of photocatalysts PCs based on surface-modified NAA-PCs. Lim et al. have explored for the first time the capabilities of NAA-GIFs functionalized with $\mathrm{TiO}_{2}\left(\mathrm{TiO}_{2}-\mathrm{NAA}-\mathrm{GIFs}\right)$ to enhance photon-to-electron conversion rates and improve photocatalytic reactions by "slow photon" effect (Figure 8) [22].
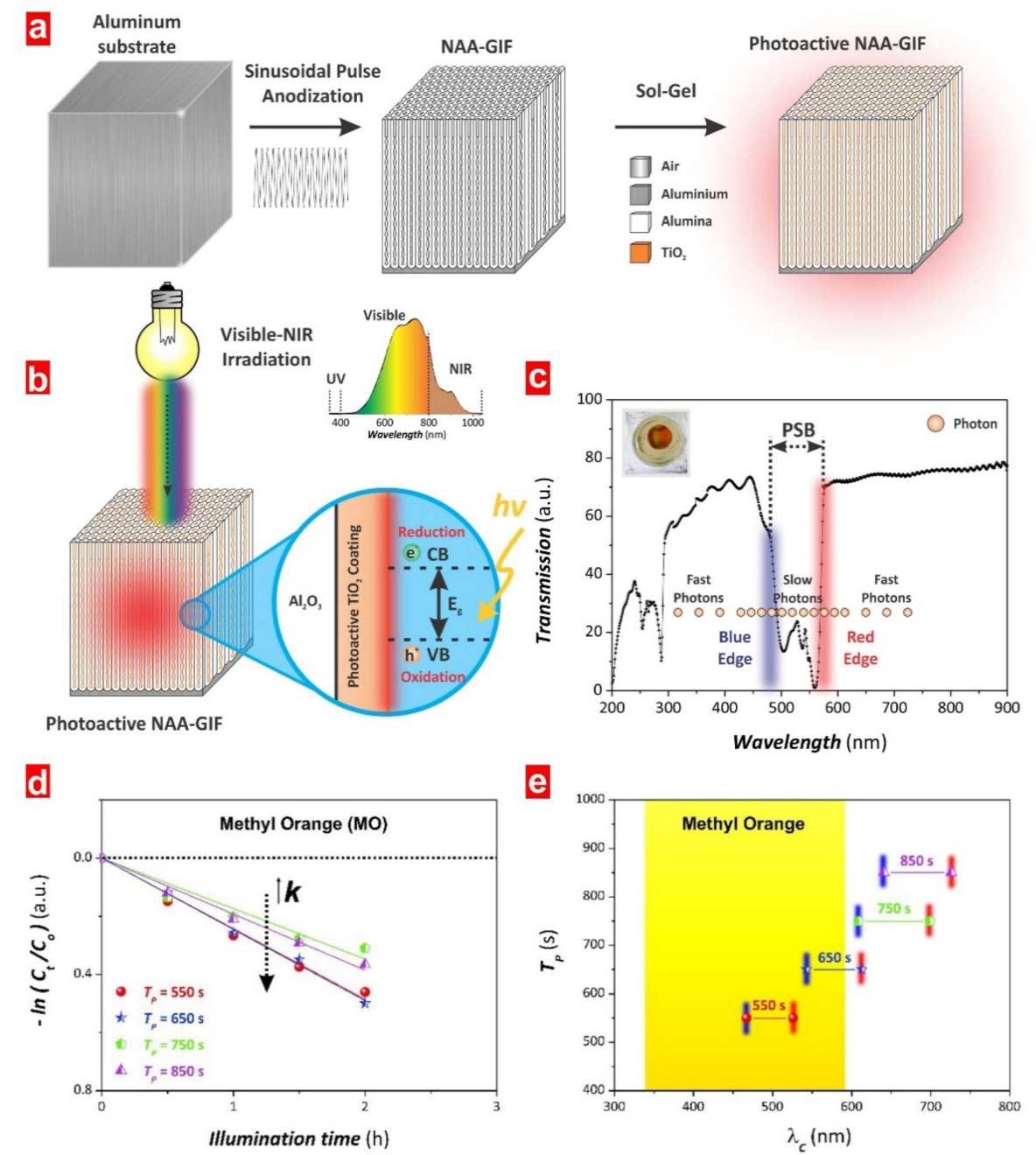

Figure 8. Applicability of $\mathrm{TiO}_{2}-\mathrm{NAA}-\mathrm{GIFs}$ in photocatalytic degradation of organics. (a) Schematic representation of the fabrication process of $\mathrm{TiO}_{2}-\mathrm{NAA}-\mathrm{GIFs}$; (b) schematic showing the utilization of $\mathrm{TiO}_{2}$-NAA-GIFs in photocatalysis under controlled visible-NIR irradiation conditions; (c) transmission spectrum of a representative $\mathrm{TiO}_{2}-\mathrm{NAA}-\mathrm{GIFs}$ showing the blue and red edges of the PSB, where photons at the blue and red edges of the PSB slow down their group velocity after interacting with the PC structure; (d) photocatalytic degradation kinetics for methyl orange (MO) by $\mathrm{TiO}_{2}-\mathrm{NAA}-\mathrm{GIFs}$ fabricated with varying anodization period $\left(T_{P}\right)$ under controlled irradiation conditions; and (e) relative position of the blue and red edges of the characteristic PSB of $\mathrm{TiO}_{2}-\mathrm{NAA}-\mathrm{GIFs}$ produced with various $T_{P}$ and the absorbance band of MO. Reproduced from [22], with copyright permission from American Chemical Society, 2018. 
NAA-GIFs were fabricated by sinusoidal pulse anodization and functionalized with photoactive layers of $\mathrm{TiO}_{2}$ through the sol-gel method. The photocatalytic performance of $\mathrm{TiO}_{2}-\mathrm{NAA}-\mathrm{GIFs}$ was assessed by studying the photodegradation of three model organic dyes (i.e., methyl orange-MO, methylene blue-MB and rhodamine B-RhoB) with well-defined absorption bands across different spectral regions under visible-NIR irradiation conditions. $\mathrm{TiO}_{2}-\mathrm{NAA}-\mathrm{GIFs}$ achieved high photocatalytic performances $(k)$ in the degradation of $\mathrm{MO}$, RhoB and MB (i.e., $k_{M O}=0.25 \mathrm{~h}^{-1}, k_{R h o B}=0.39 \mathrm{~h}^{-1}$ and $k_{M B}=2.10 \mathrm{~h}^{-1}$ ). These NAA-based PCs outperformed other forms of semiconductor photocatalysts

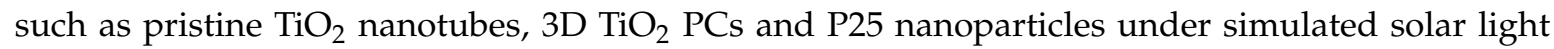
irradiation. Performance enhancements were ascribed to the "slow photon" effect, where a group of incoming photons propagate with strongly reduced group velocity and are localized in high (i.e., photocatalysts) and low (i.e., dye and pores) dielectric parts of the red and blue edges of the PSB of these PC structures, respectively. Slow photons collected by the underlying NAA-GIF structure can be efficiently utilized by the photoactive $\mathrm{TiO}_{2}$ layer to generate extra $\mathrm{e}^{-} / \mathrm{h}^{+}$pairs and increase photon-to-electron conversion rates. Spectral alignment of the characteristic PSBs of $\mathrm{TiO}_{2}-\mathrm{NAA}-\mathrm{GIFs}$ to the specific absorption bands of the organic dyes was demonstrated to significantly enhance the photodegradation rate of these organic dyes.

Lim et al. have also prepared NAA-DBRs and functionalized with photoactive $\mathrm{TiO}_{2}$ layers for assessing their photocatalytic performance associated with "slow photon" effect in the degradation of model organics under visible-NIR irradiation conditions (Figure 9) [23]. These $\mathrm{TiO}_{2}-\mathrm{NAA}-\mathrm{DBRs}$ achieved better photocatalytic performances (i.e., $k_{M O}=0.32 \mathrm{~h}^{-1}, k_{R h o B}=0.35 \mathrm{~h}^{-1}$ and $k_{M B}=3.04 \mathrm{~h}^{-1}$ ) than those of $\mathrm{TiO}_{2}$-NAA-GIFs. The measured enhanced performances were attributed to a better light collection associated with the broader and more intense characteristic PSB of NAA-DBR structures fabricated by stepwise pulse anodization (STPA). Real-life application of $\mathrm{TiO}_{2}-\mathrm{NAA}-\mathrm{DBR}$ to degrade resilient organochlorine compounds such as 4-chlorophenol in various environmental matrices and the reusability of these composite PC structures over five cycles were also demonstrated [23].
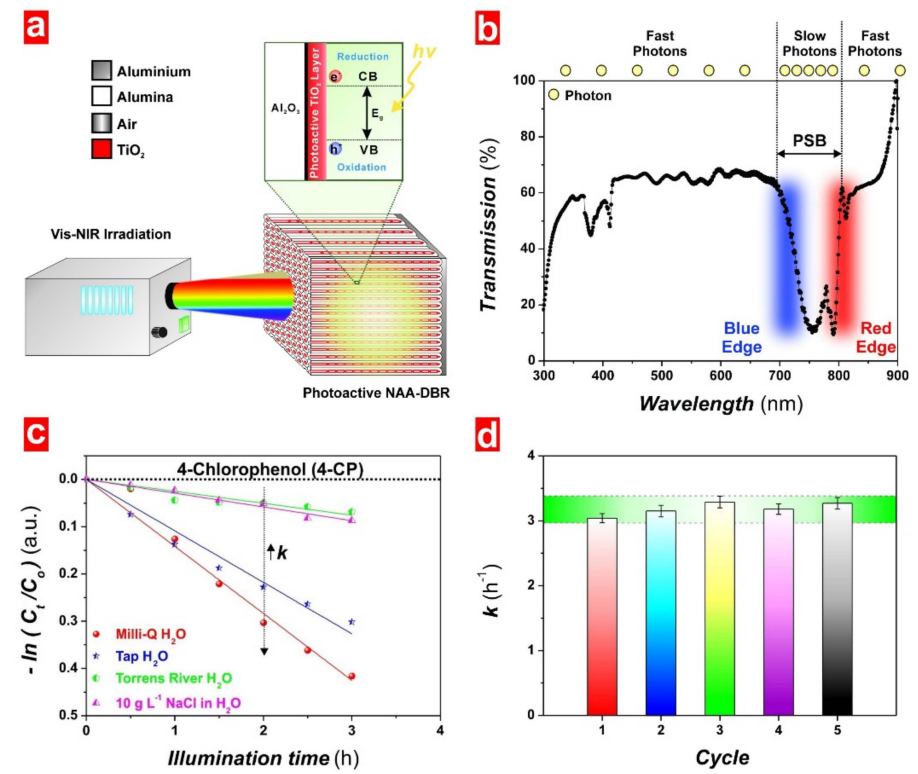

Figure 9. Applicability of $\mathrm{TiO}_{2}-\mathrm{NAA}-\mathrm{DBRs}$ in photocatalytic degradation of organics. (a) Schematic of setup used to assess the photocatalytic performance of $\mathrm{TiO}_{2}-\mathrm{NAA}-\mathrm{DBR}$ under visible-NIR irradiation conditions; (b) representative transmission spectrum of NAA-DBRs showing details of the characteristic PSB with its blue and red edges denoting reduced group velocity of photons across these spectral regions; (c) photocatalytic degradation kinetics of 4-chlorophenol (4-CP) in different aqueous matrices by $\mathrm{TiO}_{2}-\mathrm{NAA}-\mathrm{DBR}$ under controlled irradiation conditions; and (d) reusability test of $\mathrm{TiO}_{2}-\mathrm{NAA}-\mathrm{DBRs}$ on the photodegradation of methylene blue (MB) under simulated solar light irradiation. Reproduced from [23], with copyright permission from American Chemical Society, 2019. 
Liu et al. have recently fabricated $\mathrm{TiO}_{2}-\mathrm{NAA}-\mu \mathrm{CVs}$ by a combination of rationally designed sinusoidal pulse anodization and the sol-gel method and explored their applicability in photodegradation of the model organic dyes (i.e., $\mathrm{MO}$, RhoB and $\mathrm{MB}$ ) under visible-NIR irradiation conditions (Figure 10) [24]. Unlike the optical phenomena (i.e., "slow photon" effect) of other NAA-PC-based photocatalyst platforms (i.e., $\mathrm{TiO}_{2}$-NAA-GIFs and $\mathrm{TiO}_{2}-\mathrm{NAA}-\mathrm{DBRs}$ ) used to enhance the photocatalytic reactions, photocatalytic enhancements in $\mathrm{TiO}_{2}-\mathrm{NAA}-\mu \mathrm{CVs}$ are attributed to a highly efficient recirculation and confinement of incoming photons with energies within the resonance band of these PC structures.
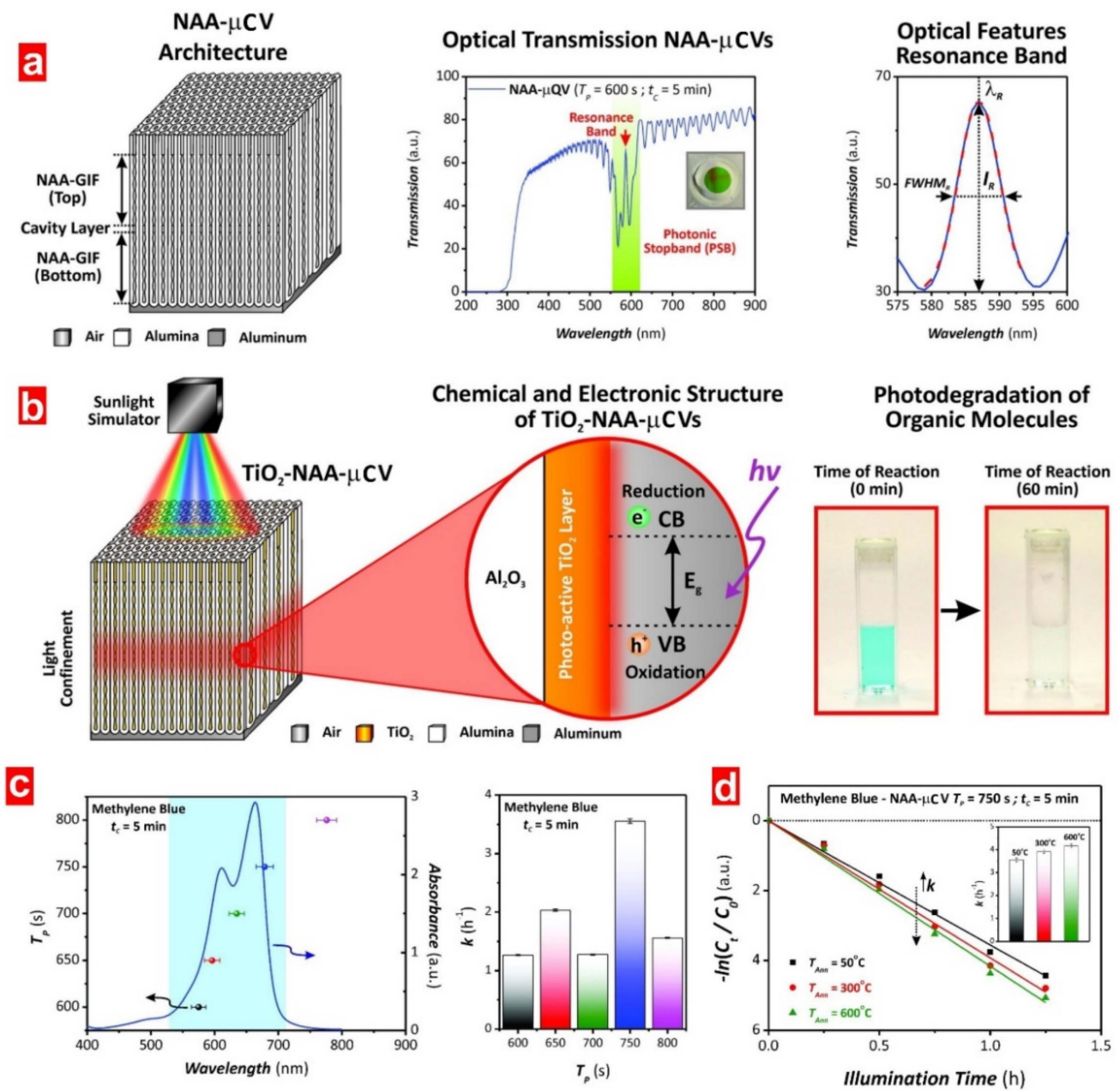

Figure 10. Applicability of $\mathrm{TiO}_{2}-\mathrm{NAA}-\mu \mathrm{CV}$ s in photocatalytic degradation of organics. (a) Illustration of the architecture of NAA- $\mu \mathrm{CVs}$ and representative transmission spectrum of a NAA- $\mu \mathrm{CV}$ with a magnified view of the resonance band and a graphical description of its optical features; (b) schematic showing the photocatalytic activity of $\mathrm{TiO}_{2}-\mathrm{NAA}-\mu \mathrm{CVs}$ under controlled visible-NIR irradiation conditions (left) and digital pictures showing the color change in $\mathrm{MB}$ from blue to transparent due to the successful photodegradation of $\mathrm{MB}$ by $\mathrm{TiO}_{2}-\mathrm{NAA}-\mu \mathrm{CVs}$ after $1 \mathrm{~h}$ (right); (c) relative position between the resonance band of $\mathrm{TiO}_{2}$-NAA- $\mu \mathrm{CVs}$ fabricated with varying anodization period $\left(T_{P}\right)$ and the absorbance spectrum of methylene blue (MB) (left) and values of kinetic constants $(k)$ for $\mathrm{TiO}_{2}$-NAA- $\mu \mathrm{CVs}$ fabricated with various $T_{P}$ (right); and (d) photocatalytic degradation kinetics of MB by representative $\mathrm{TiO}_{2}-\mathrm{NAA}-\mu \mathrm{CVs}$ annealed at different temperatures $\left(T_{A n n}\right)$ and inset showing $k$ values of these composite PC structures. Reproduced from [24], with copyright permission from the Royal Society of Chemistry, 2019.

This optical effect extends the lifetime of incident electromagnetic waves within the microcavity structure, thus increasing the probability of photon-to-semiconductor interactions and speeding up 
photocatalytic reactions due to an increased generation of charge carriers. Photocatalytic enhancements in $\mathrm{TiO}_{2}-\mathrm{NAA}-\mu \mathrm{CVs}$ were found to strongly rely on the relative position between the resonance band of these NAA-PCs and the absorbance band of organic dyes, and on the light confinement quality. These composite PC structures have shown outstanding photocatalytic performances (i.e., $k_{M O}=0.77 \mathrm{~h}^{-1}, k_{R h o B}=1.34 \mathrm{~h}^{-1}$ and $k_{M B}=3.55 \mathrm{~h}^{-1}$ ) and demonstrated superior photocatalytic activities to other NAA-PC-based and $\mathrm{TiO}_{2}-\mathrm{PC}$-based photocatalyst platforms.

The effect of the crystallographic phase of $\mathrm{TiO}_{2}$ (i.e., amorphous, anatase and rutile) modified by annealing treatment (i.e., 50, 300 and $600{ }^{\circ} \mathrm{C}$ ) on the photocatalytic degradation of $\mathrm{MB}$ by $\mathrm{TiO}_{2}-\mathrm{NAA}-\mu \mathrm{CV}$ s was also investigated. $\mathrm{TiO}_{2}-\mathrm{NAA}-\mu \mathrm{CV}$ s featuring the rutile phase outperformed their counterparts containing amorphous and anatase phases of $\mathrm{TiO}_{2}$ due to the higher tendency to trap holes and electrons for photocatalytic reactions. Lim et al. developed hybrid $\mathrm{Au}-\mathrm{TiO}_{2}-\mathrm{NAA}-\mathrm{DBRs}$ photocatalyst platforms integrating slow photons and LSPR effects in the same photocatalyst platforms (Figure 11) [25]. Au films were deposited on the top surfaces of $\mathrm{TiO}_{2}$-NAA-DBRs, and photocatalytic degradation of the MB molecules under visible-NIR illumination was used as reference reaction to assess enhancements associated with slow photon-LSPR coupling effects. However, this study demonstrated that photocatalytic enhancements are more strongly determined by "slow photon" effect than by LSPR effect due to the localized nature of generated surface plasmons on the top surface of the composite PC structures. Note, the obtained results revealed that these optical phenomena must be finely coupled in order to improve the design of noble metal-NAA-based photoactive PCs. 

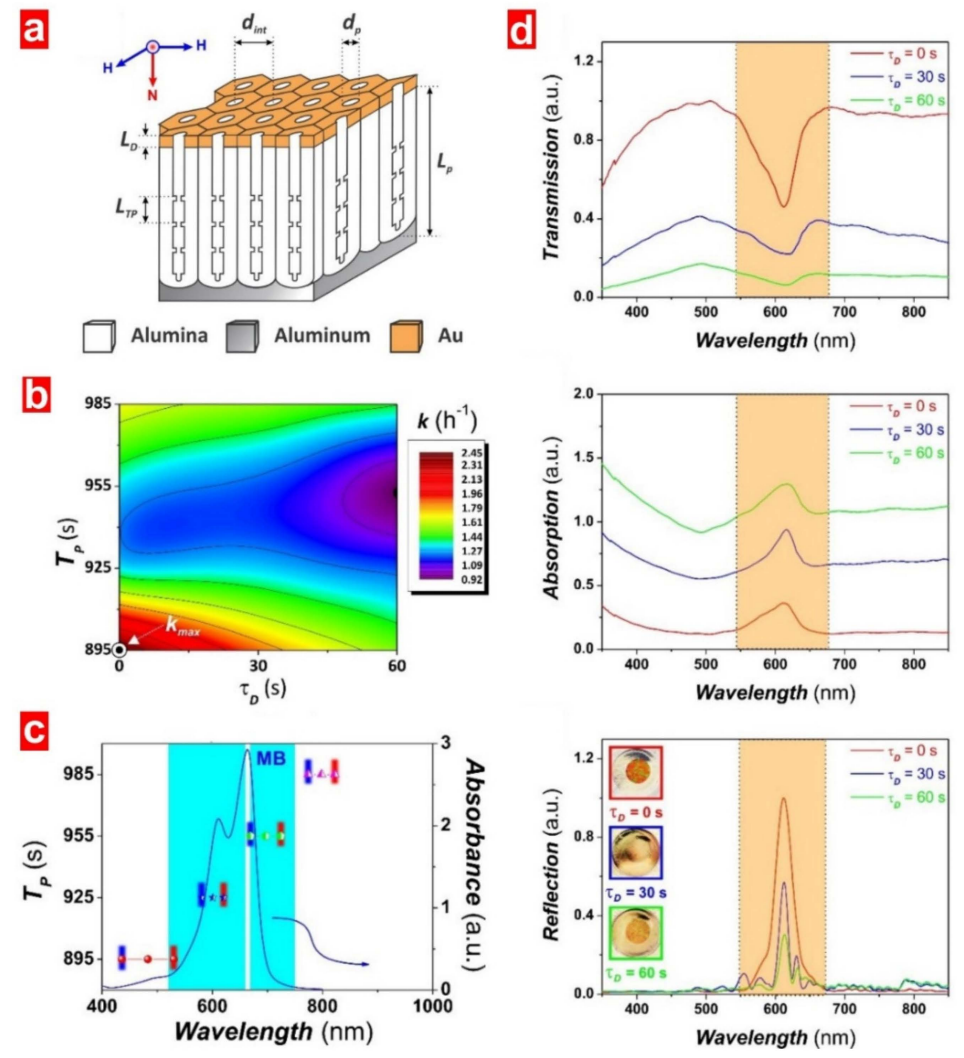

Figure 11. Applicability of $\mathrm{Au}-\mathrm{TiO}_{2}-\mathrm{NAA}-\mathrm{DBRs}$ in photocatalytic degradation of organics. (a) Illustration describing the geometric features of Au-coated NAA-DBRs (i.e., total pore length- $L_{p}$, interpore distance $-d_{\text {int }}$; pore diameter $-d_{p}$; period length $-L_{T P}$; Au thickness $\left.-L_{D}\right)$; (b) representative contour plot showing the combined effect of anodization period $\left(T_{P}\right)$ and $\mathrm{Au}$ deposition time $\left(\tau_{D}\right)$ on $k$ values for photodegradation of $\mathrm{MB}$ by $\mathrm{Au}-\mathrm{TiO}_{2}-\mathrm{NAA}-\mathrm{DBRs}$; (c) representative relative position of the blue and red edges of the characteristic PSB of $\mathrm{Au}-\mathrm{TiO}_{2}-\mathrm{NAA}-\mathrm{DBR}$ produced with various $T_{P}$ and the absorbance band of $\mathrm{MB}$; and (d) optical characterization of a representative $\mathrm{Au}-\mathrm{TiO}_{2}$-NAA-DBR demonstrating localized position of the Au layer in the composite PC photocatalyst platform. Reproduced from [25], with copyright permission from the Royal Society of Chemistry, 2019.

\section{Conclusions}

This review provides a comprehensive overview of fundamental aspects and recent progress in EENMs as photocatalyst platforms for photocatalytic and photo-electrocatalytic applications. Over the past ten years, the potential of these nanoporous materials in pollution degradation and hydrogen evolution has been demonstrated. EENMs provide many advantages to drive photocatalytic reactions efficiently, including highly defined tailor-made self-organized nanoporous structures, outstanding control over light to harness electromagnetic waves and efficient management of charge carrier separation.

The structure of EENMs can be precisely tailored in various types of photonic crystal by anodization - an inexpensive, simple and fully scalable nanofabrication approach. These PC structures provide new opportunities to harvest incident photons by different optical phenomena such as strong localization, trapping, slowing and recirculation. The optimal structural and chemical design of EENMs makes it possible to significantly enhance photon-to-electron conversion rates for several photocatalytic applications. However, more systematic experimental investigations will be needed to fully develop this technology for high performance, real-life photocatalytic applications. Furthermore, the ability to modify EENMs by a broad range of chemical and physical methods can endow these materials with desirable properties to achieve unprecedented performances by rational design and integration of 
optical and electronic structures. There remain fundamental questions regarding the optimal design of photonic and electronic band structures that can maximize the performance of hybrid semiconductor PC structures. The use of new crystalline structures, geometric features and chemical composition of EENMs, including modification of the inner surface with advanced carbonaceous materials, will be crucial aspects to overcome existing constraints in photocatalysis technology. The existing studies shown throughout this review demonstrate that EENMs have promising potential for a broad range of photocatalytic and photo-electrocatalytic applications. The photocatalytic performance and selectivity of these unique materials are found in many cases to be superior to existing photocatalysts such as nanoparticulate systems and inverted opals. Therefore, it is expected that future developments in EENMs might pave the way to new and exciting opportunities to expand the applicability of this technology across classic photocatalysis fields such as pollution remediation and hydrogen generation and cutting edge applications such as $\mathrm{CO}_{2}$ reduction, highly selective organic synthesis, biomedical devices and self-cleaning surfaces.

Funding: This research was funded by the Australian Research Council (ARC) through the grant number CE140100003, the School of Chemical Engineering and Advanced Materials, the University of Adelaide (DVCR 'Research for Impact' initiative), the Institute for Photonics and Advanced Sensing (IPAS), the ARC Centre of Excellence for Nanoscale BioPhotonics (CNBP), the Deutsche Forschungsgemeinschaft (DFG, German Research Foundation) through the project number \#192346071-SFB 986.

Conflicts of Interest: The authors declare no conflict of interest.

\section{References}

1. Fox, M.A.; Dulay, M.T. Heterogeneous photocatalysis. Chem. Rev. 1993, 93, 341-357. [CrossRef]

2. Fujishima, A.; Honda, K. Electrochemical photolysis of water at a semiconductor electrode. Nature 1972, 238, 37-38. [CrossRef] [PubMed]

3. Yan, G.; Zhang, M.; Hou, J.; Yang, J. Photoelectrochemical and photocatalytic properties of N+S co-doped $\mathrm{TiO}_{2}$ nanotube array films under visible light irradiation. Mater. Chem. Phys. 2011, 129, 553-557. [CrossRef]

4. Agarwal, P.; Paramasivam, I.; Shrestha, N.K.; Schmuki, P. $\mathrm{MoO}_{3}$ in self-organized $\mathrm{TiO}_{2}$ nanotubes for enhanced photocatalytic activity. Chem. Asian J. 2010, 5, 66-69. [CrossRef] [PubMed]

5. Liu, Z.; Zhang, X.; Nishimoto, S.; Murakami, T.; Fujishima, A. Efficient photocatalytic degradation of gaseous acetaldehyde by highly ordered $\mathrm{TiO}_{2}$ nanotube arrays. Environ. Sci. Technol. 2008, 42, 8547-8551. [CrossRef] [PubMed]

6. In, S.; Nielsen, M.G.; Vesborg, P.C.K.; Hou, Y.; Abrams, B.L.; Henriksen, T.R.; Hansen, O.; Chorkendorff, I. Photocatalytic methane decomposition over vertically aligned transparent $\mathrm{TiO}_{2}$ nanotube arrays. Chem. Commun. 2011, 47, 2613-2615. [CrossRef] [PubMed]

7. Das, C.; Roy, P.; Yang, M.; Jha, H.; Schmuki, P. Nb doped $\mathrm{TiO}_{2}$ nanotubes for enhanced photoelectrochemical water-splitting. Nanoscale 2011, 3, 3094-3096. [CrossRef]

8. Liu, N.; Schneider, C.; Freitag, D.; Hartmann, M.; Venkatesan, U.; Müller, J.; Spiecker, E.; Schmuki, P. Black $\mathrm{TiO}_{2}$ nanotubes: Cocatalyst-free open-circuit hydrogen generation. Nano Lett. 2014, 14, 3309-3313. [CrossRef]

9. Varghese, O.K.; Paulose, M.; LaTempa, T.J.; Grimes, C.A. High-rate solar photocatalytic conversion of $\mathrm{CO}_{2}$ and water vapor to hydrocarbon fuels. Nano Lett. 2009, 9, 731-737. [CrossRef]

10. Kandy, M.M.; Gaikar, V.G. Photocatalytic reduction of $\mathrm{CO}_{2}$ using $\mathrm{CdS}$ nanorods on porous anodic alumina support. Mater. Res. Bull. 2018, 102, 440-449. [CrossRef]

11. Hirakawa, H.; Hashimoto, M.; Shiraishi, Y.; Hirai, T. Photocatalytic conversion of nitrogen to ammonia with water on surface oxygen vacancies of titanium dioxide. J. Am. Chem. Soc. 2017, 140, 10929-10936. [CrossRef] [PubMed]

12. Yang, J.; Guo, Y.; Jiang, R.; Qin, F.; Zhang, H.; Lu, W.; Wang, J.; Yu, J.C. High-efficiency “working-in-tandem” nitrogen photofixation achieved by assembling plasmonic gold nanocrystals on ultrathin Titania nanosheets. J. Am. Chem. Soc. 2018, 140, 8497-8508. [CrossRef] [PubMed]

13. Tripathy, J.; Lee, K.; Schmuki, P. Tuning the selectivity of photocatalytic synthetic reactions using modified $\mathrm{TiO}_{2}$ nanotubes. Angew. Chem. Int. Ed. 2014, 53, 12605-12608. 
14. Paramasivam, I.; Avhale, A.; Inayat, A.; Boesmann, A.; Schmuki, P.; Schwieger, W. MFI-type (ZSM-5) zeolite-filled $\mathrm{TiO}_{2}$ nanotubes for enhanced photocatalytic activity. Nanotechnology 2009, 20, 225607. [CrossRef]

15. Qu, Y.; Duan, X. Progress, challenge and perspective of heterogeneous photocatalysts. Chem. Soc. Rev. 2013, 42, 2568-2580. [CrossRef]

16. Paramasivam, I.; Jha, H.; Liu, N.; Schmuki, P. A review of photocatalysis using self-organized $\mathrm{TiO}_{2}$ nanotubes and other ordered oxide nanostructures. Small 2012, 8, 3073-3103. [CrossRef]

17. Molina-Reyes, J.; Romero-Moran, A.; Uribe-Vargas, H.; Lopez-Ruiz, B.; Sanchez-Salas, J.L.; Ortega, E.; Ponce, A.; Morales-Sanchez, A.; Lopez-Huerta, F.; Zuñiga-Islas, C. Study on the photocatalytic activity of titanium dioxide nanostructures: Nanoparticles, nanotubes and ultra-thin films. Catal. Today 2020, 341, 2-12. [CrossRef]

18. Liu, N.; Paramasivam, I.; Yang, M.; Schmuki, P. Some critical factors for photocatalysis on self-organized $\mathrm{TiO}_{2}$ nanotubes. J. Solid State Electrochem. 2012, 16, 3499-3504. [CrossRef]

19. Lee, H.; Park, T.-H.; Jang, D.-J. Preparation of anatase $\mathrm{TiO}_{2}$ nanotube arrays dominated by highly reactive facets via anodization for high photocatalytic performances. New J. Chem. 2016, 40, 8737-8744. [CrossRef]

20. Lee, K.; Hahn, R.; Altomare, M.; Selli, E.; Schmuki, P. Intrinsic Au decoration of growing $\mathrm{TiO}_{2}$ nanotubes and formation of a high-efficiency photocatalyst for $\mathrm{H}_{2}$ production. Adv. Mater. 2013, 25, 6133-6137. [CrossRef]

21. Paramasivam, I.; Macak, J.M.; Schmuki, P. Photocatalytic activity of $\mathrm{TiO}_{2}$ nanotube layers loaded with $\mathrm{Ag}$ and Au nanoparticles. Electrochem. Commun. 2008, 10, 71-75. [CrossRef]

22. Lim, S.Y.; Law, C.S.; Markovic, M.; Kirby, J.K.; Abell, A.D.; Santos, A. Engineering the slow photon effect in photoactive nanoporous anodic alumina gradient-index filters for photocatalysis. ACS Appl. Mater. Interfaces 2018, 10, 24124-24136. [CrossRef] [PubMed]

23. Lim, S.Y.; Law, C.S.; Markovic, M.; Marsal, L.F.; Voelcker, N.H.; Abell, A.D.; Santos, A. Rational management of photons for enhanced photocatalysis in structurally-colored nanoporous anodic alumina photonic crystals. ACS Appl. Energy Mater. 2019, 2, 1169-1184. [CrossRef]

24. Liu, L.; Lim, S.Y.; Law, C.S.; Jin, B.; Abell, A.D.; Ni, G.; Santos, A. Light-confining semiconductor nanoporous anodic alumina optical microcavities for photocatalysis. J. Mater. Chem. A 2019, 7, 22514-22529. [CrossRef]

25. Lim, S.Y.; Law, C.S.; Liu, L.; Markovic, M.; Abell, A.D.; Santos, A. Integrating surface plasmon resonance and slow photon effects in nanoporous anodic alumina photonic crystals for photocatalysis. Catal. Sci. Technol. 2019, 9, 3158-3176. [CrossRef]

26. Sopha, H.; Krbal, M.; Ng, S.; Prikryl, J.; Zazpe, R.; Yam, F.K.; Macak, J.M. Highly efficient photoelectrochemical and photocatalytic anodic $\mathrm{TiO}_{2}$ nanotube layers with additional $\mathrm{TiO}_{2}$ coating. Appl. Mater. Today 2017, 9, 104-110. [CrossRef]

27. Sopha, H.; Baudys, M.; Krbal, M.; Zazpe, R.; Prikryl, J.; Krysa, J.; Macak, J.M. Scaling up anodic $\mathrm{TiO}_{2}$ nanotube layers for gas phase photocatalysis. Electrochem. Commun. 2018, 97, 91-95. [CrossRef]

28. Nguyen, N.T.; Altomare, M.; Yoo, J.E.; Schmuki, P. Efficient photocatalytic $\mathrm{H}_{2}$ evolution: Controlled dewetting-dealloying to fabricate site-selective high-activity nanoporous Au particles on highly ordered $\mathrm{TiO}_{2}$ nanotube arrays. Adv. Mater. 2015, 27, 3208-3215. [CrossRef]

29. Hejazi, S.; Altomare, M.; Mohajernia, S.; Schmuki, P. Composition gradients in sputtered Ti-Au alloys: Site-selective $\mathrm{Au}$ decoration of anodic $\mathrm{TiO}_{2}$ nanotubes for photocatalytic $\mathrm{H}_{2}$ evolution. ACS Appl. Nano Mater. 2019, 2, 4018-4025. [CrossRef]

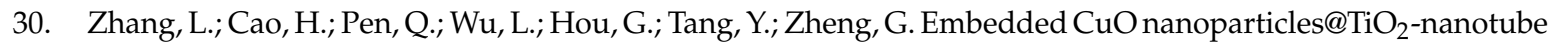
arrays for photoelectrocatalytic reduction of $\mathrm{CO}_{2}$ to methanol. Electrochim. Acta 2018, 283, 1507-1513. [CrossRef]

31. Banerjee, S.; Mohapatra, S.K.; Das, P.P.; Misra, M. Synthesis of coupled semiconductor by filling $1 \mathrm{D}^{\mathrm{TiO}} 2$ nanotubes with CdS. Chem. Mater. 2008, 20, 6784-6791. [CrossRef]

32. Tsui, L.-K.; Xu, Y.; Dawidowski, D.; Cafiso, D.; Zangari, G. Efficient water oxidation kinetics and enhanced electron transport in $\mathrm{Li}$-doped $\mathrm{TiO}_{2}$ nanotube photoanodes. J. Mater. Chem. A 2016, 4, 19070-19077.

33. Le, P.H.; Hieu, L.T.; Lam, T.-N.; Hang, N.T.N.; Truong, N.V.; Tuyen, L.T.C.; Phong, P.T.; Leu, J. Enhanced photocatalytic performance of nitrogen-doped $\mathrm{TiO}_{2}$ nanotube arrays using a simple annealing process. Micromachines 2018, 9, 618. [CrossRef] [PubMed]

34. Zhang, Z.; Wang, P. Optimization of photoelectrochemical water splitting performance on hierarchical $\mathrm{TiO}_{2}$ nanotube arrays. Energy Environ. Sci. 2012, 5, 6506-6512. [CrossRef] 
35. Lian, Z.; Wang, W.; Xiao, S.; Li, X.; Cui, Y.; Zhang, D.; Li, G.; Li, H. Plasmonic silver quantum dots coupled with hierarchical $\mathrm{TiO}_{2}$ nanotube arrays photoelectrodes for efficient visible-light photoelectrocatalytic hydrogen evolution. Sci. Rep. 2015, 5, 10461. [CrossRef]

36. Zhang, Z.; Zhang, L.; Hedhili, M.N.; Zhang, H.; Wang, P. Plasmonic gold nanocrystals coupled with photonic crystal seamlessly on $\mathrm{TiO}_{2}$ nanotube photoelectrodes for efficient visible light photoelectrochemical water splitting. Nano Lett. 2013, 13, 14-20. [CrossRef]

37. Zhou, X.; Liu, N.; Schmuki, P. Photocatalysis with $\mathrm{TiO}_{2}$ nanotubes: "colorful" reactivity and designing site-specific photocatalytic centers into $\mathrm{TiO}_{2}$ nanotubes. ACS Catal. 2017, 7, 3210-3235. [CrossRef]

38. Chiarello, G.L.; Zuliani, A.; Ceresoli, D.; Martinazzo, R.; Selli, E. Exploiting the photonic crystal properties of $\mathrm{TiO}_{2}$ nanotube arrays to enhance photocatalytic hydrogen production. ACS Catal. 2016, 6, 1345-1353. [CrossRef]

39. Zheng, X.; Meng, S.; Chen, J.; Wang, J.; Xian, J.; Shao, Y.; Fu, X.; Li, D. Titanium dioxide photonic crystals with enhanced photocatalytic activity: Matching photonic band gaps of $\mathrm{TiO}_{2}$ to the absorption peaks of dyes. J. Phys. Chem. C 2013, 117, 21263-21273. [CrossRef]

40. Zhang, L.; Baumanis, C.; Robben, L.; Kandiel, T.; Bahnemann, D. $\mathrm{Bi}_{2} \mathrm{WO}_{6}$ inverse opals: Facile fabrication and efficient visible-light driven photocatalytic and photoelectrochemical water-splitting activity. Small 2011, 7, 2714-2720. [CrossRef]

41. Li, X.; Zhen, X.; Meng, S.; Xian, J.; Shao, Y.; Fu, X.; Li, D. Structuring $\beta-\mathrm{Ga}_{2} \mathrm{O}_{3}$ photonic crystal photocatalyst for efficient degradation of organic pollutants. Environ. Sci. Technol. 2013, 47, 9911-9917. [CrossRef]

42. Meng, S.; Li, D.; Wang, P.; Zheng, X.; Wang, J.; Chen, J.; Fang, J.; Fu, X. Probing photonic effect on photocatalytic degradation of dyes based on 3D inverse opal $\mathrm{ZnO}$ photonic crystal. RSC Adv. 2013, 3, 17021-17028. [CrossRef]

43. Meng, S.; Li, D.; Fu, X.; Fu, X. Integrating photonic bandgaps with surface plasmon resonance for the enhancement of visible-light photocatalytic performance. J. Mater. Chem. A 2015, 3, 23501-23511. [CrossRef]

44. Curti, M.; Schneider, J.; Bahnemann, D.W.; Mendive, C.B. Inverse opal photonic crystals as a strategy to improve photocatalysis: Underexplored questions. J. Phys. Chem. Lett. 2015, 6, 3903-3910. [CrossRef] [PubMed]

45. Santos, A. Nanoporous anodic alumina photonic crystals: Fundamentals, developments and perspectives. J. Mater. Chem. C 2017, 5, 5581-5599. [CrossRef]

46. Ermolaev, G.A.; Kushnir, S.E.; Sapoletova, N.A.; Napolskii, K.S. Titania photonic crystals with precise photonic band gap position via anodizing with voltage versus optical path length modulation. Nanomaterials 2019, 9, 651. [CrossRef] [PubMed]

47. Diggle, J.W.; Downie, T.C.; Goulding, C.W. Anodic oxide films on aluminum. Chem. Rev. 1969, 69, $365-405$. [CrossRef]

48. Masuda, H.; Fukuda, K. Ordered metal nanohole arrays made by a two-step replication of honeycomb structures of anodic alumina. Science 1995, 268, 1466-1468. [CrossRef]

49. Masuda, H.; Hasegawa, F.; Ono, S. Self-ordering of cell arrangement of anodic porous alumina formed in sulfuric acid solution. J. Electrochem. Soc. 1997, 144, L127-L130. [CrossRef]

50. Schwirn, K.; Lee, W.; Hillebrand, R.; Steinhart, M.; Nielsch, K.; Gösele, U. Self-ordered anodic aluminium oxide formed by $\mathrm{H}_{2} \mathrm{SO}_{4}$ hard anodization. ACS Nano 2008, 2, 302-310. [CrossRef]

51. Lee, W.; Ji, R.; Gösele, U.; Nielsch, K. Fast fabrication of long-range ordered porous alumina membranes by hard anodization. Nat. Mater. 2006, 5, 741-747. [CrossRef] [PubMed]

52. Masuda, H.; Yada, K.; Osaka, A. Self-ordering of cell configuration of anodic porous alumina with large-size pores in phosphoric acid solution. Jpn. J. Appl. Phys. 1998, 37, L1340-L1342. [CrossRef]

53. Macak, J.M.; Sirotna, K.; Schmuki, P. Self-organized porous titanium dioxide prepared in $\mathrm{Na}_{2} \mathrm{SO}_{4} / \mathrm{NaF}$ electrolytes. Electrochim. Acta 2005, 50, 3679-3684. [CrossRef]

54. Yoriya, S.; Paulose, M.; Varghese, O.K.; Mor, G.K.; Grimes, C.A. Fabrication of vertically oriented $\mathrm{TiO}_{2}$ nanotube arrays using dimethyl sulfoxide electrolytes. J. Phys. Chem. C 2007, 111, 13770-13776. [CrossRef]

55. Paulose, M.; Prakasam, H.E.; Varghese, O.K.; Peng, L.; Popat, K.C.; Mor, G.K.; Desai, T.A.; Grimes, C.A. TiO 2 nanotube arrays of $1000 \mu \mathrm{m}$ length by anodization of titanium foil: Phenol red diffusion. J. Phys. Chem. C 2007, 111, 14992-14997. [CrossRef]

56. Allam, N.K.; Grimes, C.A. Formation of vertically oriented $\mathrm{TiO}_{2}$ nanotube arrays using a fluoride free $\mathrm{HCl}$ aqueous electrolyte. J. Phys. Chem. C 2007, 111, 13028-13032. [CrossRef] 
57. Hahn, R.; Macak, J.M.; Schmuki, P. Rapid anodic growth of $\mathrm{TiO}_{2}$ and $\mathrm{WO}_{3}$ nanotubes in fluoride free electrolytes. Electrochem. Commun. 2007, 9, 947-952. [CrossRef]

58. Macak, J.M.; Albu, S.P.; Schmuki, P. Towards ideal hexagonal self-ordering of $\mathrm{TiO}_{2}$ nanotubes. Phys. Stat. Sol. (RRL) 2007, 1, 181-183. [CrossRef]

59. Shin, Y.; Lee, S. Self-organized regular arrays of anodic $\mathrm{TiO}_{2}$ nanotubes. Nano Lett. 2008, 8, 3171-3173. [CrossRef]

60. Mohapatra, S.K.; John, S.E.; Banerjee, S.; Misra, M. Water photooxidation by smooth and ultrathin $\alpha-\mathrm{Fe}_{2} \mathrm{O}_{3}$ nanotube arrays. Chem. Mater. 2009, 21, 3048-3055. [CrossRef]

61. Albu, S.P.; Ghicov, A.; Schmuki, P. High aspect ratio, self-ordered iron oxide nanopores formed by anodization of Fe in ethylene glycol/ $\mathrm{NH}_{4} \mathrm{~F}$ electrolytes. Phys. Stat. Sol. (RRL) 2009, 3, 64-66. [CrossRef]

62. Berger, S.; Jakubka, F.; Schmuki, P. Formation of hexagonally ordered nanoporous anodic zirconia. Electrochem. Commun. 2008, 10, 1916-1919. [CrossRef]

63. Tsuchiya, H.; Macak, J.M.; Sieber, I.; Taveira, L.; Ghicov, A.; Sirotna, K.; Schmuki, P. Self-organized porous $\mathrm{WO}_{3}$ formed in NaF electrolytes. Electrochem. Commun. 2005, 7, 295-298. [CrossRef]

64. Choi, J.; Lim, J.H.; Lee, S.C.; Chang, J.H.; Kim, K.J.; Cho, M.A. Porous niobium oxide films prepared by anodization in $\mathrm{HF} / \mathrm{H}_{3} \mathrm{PO}_{4}$. Electrochim. Acta 2006, 51, 5502-5507. [CrossRef]

65. Wei, W.; Lee, K.; Shaw, S.; Schmuki, P. Anodic formation of high aspect ratio, self-ordered $\mathrm{Nb}_{2} \mathrm{O}_{5}$ nanotubes. Chem. Commun. 2012, 48, 4244-4246. [CrossRef] [PubMed]

66. Berger, S.; Jakubka, F.; Schmuki, P. Self-ordered hexagonal nanoporous hafnium oxide and transition to aligned $\mathrm{HfO}_{2}$ nanotube layers. Electrochem. Solid-State Lett. 2009, 12, K45-K48. [CrossRef]

67. Yang, Y.; Albu, S.P.; Kim, D.; Schmuki, P. Enabling the anodic growth of highly ordered $\mathrm{V}_{2} \mathrm{O}_{5}$ nanoporous/nanotubular structures. Angew. Chem. Int. Ed. 2011, 50, 9071-9075. [CrossRef]

68. Shen, Q.; Chen, Z.; Huang, X.; Liu, M.; Zhao, G. High-yield and selective photoelectrocatalytic reduction of $\mathrm{CO}_{2}$ to formate by metallic copper decorated $\mathrm{Co}_{3} \mathrm{O}_{4}$ nanotube arrays. Environ. Sci. Technol. 2015, 45, 5828-5835. [CrossRef]

69. Roy, P.; Berger, S.; Schmuki, P. $\mathrm{TiO}_{2}$ nanotubes: Synthesis and applications. Angew. Chem. Int. Ed. 2011, 50, 2904-2939. [CrossRef]

70. Law, C.S.; Lim, S.Y.; Abell, A.D.; Voelcker, N.H.; Santos, A. Nanoporous anodic alumina photonic crystals for optical chemo- and biosensing: Fundamentals, advances, and perspectives. Nanomaterials 2018, 8, 788. [CrossRef]

71. Macak, J.M. Self-organized anodic $\mathrm{TiO}_{2}$ nanotubes: Functionalities and applications due to a secondary material. In Electrochemically Engineered Nanoporous Materials: Methods, Properties and Applications, 1st ed.; Losic, D., Santos, A., Eds.; Springer International Publishing: Cham, Switzerland, 2015; Volume 220, pp. 65-92. ISBN 978-3-319-20346-1.

72. Nah, Y.-C.; Paramasivam, I.; Schmuki, P. Doped $\mathrm{TiO}_{2}$ and $\mathrm{TiO}_{2}$ nanotubes: Synthesis and applications. ChemPhysChem 2010, 11, 2698-2713. [CrossRef] [PubMed]

73. Di Valentin, C.; Finazzi, E.; Pacchioni, G.; Selloni, A.; Livraghi, S.; Paganini, M.C.; Giamello, E. N-doped $\mathrm{TiO}_{2}$ : Theory and experiment. Chem. Phys. 2007, 339, 44-56. [CrossRef]

74. Park, J.H.; Kim, S.; Bard, A.J. Novel carbon-doped $\mathrm{TiO}_{2}$ nanotube arrays with high aspect ratios for efficient solar water splitting. Nano Lett. 2006, 6, 24-28. [CrossRef] [PubMed]

75. Ghicov, A.; Macak, J.M.; Tsuchiya, H.; Kunze, J.; Haeublein, V.; Frey, L.; Schmuki, P. Ion implantation and annealing for an efficient $\mathrm{N}$-doping of $\mathrm{TiO}_{2}$ nanotubes. Nano Lett. 2006, 6, 1080-1082. [CrossRef]

76. Siuzdak, K.; Szkoda, M.; Lisowska-Oleksiak, A.; Grochowska, K.; Karczewski, J.; Ryl, J. Thin layer of ordered boron-doped $\mathrm{TiO}_{2}$ nanotubes fabricated in a novel type of electrolyte and characterized by remarkably improved photoactivity. Appl. Surf. Sci. 2015, 357, 942-950. [CrossRef]

77. Xue, C.; Hu, S.; Chang, Q.; Li, Y.; Liu, X.; Yang, J. Fluoride doped $\mathrm{SrTiO}_{3} / \mathrm{TiO}_{2}$ nanotube arrays with a double layer walled structure for enhanced photocatalytic properties and bioactivity. RSC Adv. 2017, 7, 49759-49768. [CrossRef]

78. Momeni, M.M.; Ghayeb, Y.; Ghonchegi, Z. Fabrication and characterization of copper doped $\mathrm{TiO}_{2}$ nanotube arrays by in situ electrochemical method as efficient visible-light photocatalyst. Ceram. Int. 2015, 41, 8735-8741. [CrossRef] 
79. Mazierski, P.; Lisowski, W.; Grzyb, T.; Winiarski, M.J.; Klimczuk, T.; Mikolajczyk, A.; Flisikowski, J.; Hirsch, A.; Kolakowska, A.; Puzyn, T.; et al. Enhanced photocatalytic properties of lanthanide- $\mathrm{TiO}_{2}$ nanotubes: An experimental and theoretical study. Appl. Catal. B Environ. 2017, 205, 376-385. [CrossRef]

80. Ghicov, A.; Macak, J.M.; Tsuchiya, H.; Kunze, J.; Haeublein, V.; Kleber, S.; Schmuki, P. TiO 2 nanotube layers. Dose effects during nitrogen doping by ion implantation. Chem. Phys. Lett. 2006, 419, 426-429. [CrossRef]

81. Kobayashi, N.; Tanoue, H. Nitrogen ion implantation into ZrN thin films. Nucl. Instrum. Methods Phys. Res. 1989, 39, 746-749. [CrossRef]

82. Tsujide, T.; Nojiri, M.; Kitagawa, H. Formation of silicon nitride compound layers by high-dose nitrogen implantation. Appl. Phys. 1980, 51, 1605-1610. [CrossRef]

83. Kim, D.; Fujimoto, S.; Schmuki, P.; Tsuchiya, H. Nitrogen doped anodic $\mathrm{TiO}_{2}$ nanotubes grown from nitrogen-containing Ti alloys. Electrochem. Commun. 2008, 10, 910-913. [CrossRef]

84. Paramasivam, I.; Nah, Y.-C.; Das, C.; Shrestha, N.K.; Schmuki, P. $\mathrm{WO}_{3} / \mathrm{TiO}_{2}$ nanotubes with strongly enhanced photocatalytic activity. Chem. Eur. J. 2010, 16, 8993-8997. [CrossRef] [PubMed]

85. Das, C.; Paramasivam, I.; Liu, N.; Schmuki, P. Photoelectrochemical and photocatalytic activity of tungsten doped $\mathrm{TiO}_{2}$ nanotube layers in the near visible region. Electrochim. Acta 2011, 56, 10557-10561. [CrossRef]

86. Altomare, M.; Lee, K.; Killian, M.S.; Selli, E.; Schmuki, P. Ta-doped $\mathrm{TiO}_{2}$ nanotubes for enhanced solar-light photoelectrochemical water splitting. Chem. Eur. J. 2013, 19, 5841-5844. [CrossRef]

87. Roy, P.; Das, C.; Lee, K.; Hahn, R.; Ruff, T.; Moll, M.; Schmuki, P. Oxide nanotubes on Ti-Ru alloys: Strongly enhanced and stable photoelectrochemical activity for water splitting. J. Am. Chem. Soc. 2011, 133, 5629-5631. [CrossRef]

88. Yoo, H.; Choi, Y.W.; Choi, J. Ruthenium oxide-doped $\mathrm{TiO}_{2}$ nanotubes by single-step anodization for water-oxidation applications. J. ChemCatChem 2015, 7, 643-647. [CrossRef]

89. Enachi, M.; Guix, M.; Braniste, T.; Postolache, V.; Ciobanu, V.; Ursaki, V.; Schmidt, O.G.; Tiginyanu, I. Photocatalytic properties of $\mathrm{TiO}_{2}$ nanotubes doped with Ag, Au and Pt or covered by Ag, Au and Pt nanodots. Surf. Eng. Appl. Electrochem. 2015, 51, 3-8. [CrossRef]

90. Nakata, K.; Liu, B.; Ishikawa, Y.; Sakai, M.; Saito, H.; Ochiai, T.; Sakai, H.; Murakami, T.; Abe, M.; Takagi, K.; et al. Fabrication and photocatalytic properties of $\mathrm{TiO}_{2}$ nanotube arrays modified with phosphate. Chem. Lett. 2011, 40, 1107-1109. [CrossRef]

91. Su, Y.; Zhang, X.; Zhou, M.; Han, S.; Lei, L. Preparation of high efficient photoelectrode of N-F-codoped TiO 2 nanotubes. J. Photochem. Photobiol. A 2008, 194, 152-160. [CrossRef]

92. Zhang, F.; Wang, X.; Liu, H.; Liu, C.; Wan, Y.; Long, Y.; Cai, Z. Recent advances and applications of semiconductor photocatalytic technology. Appl. Sci. 2019, 9, 2489. [CrossRef]

93. Lu, D.; Zhang, M.; Zhang, Z.; Li, Q.; Wang, X.; Yang, J. Self-organized vanadium and nitrogen co-doped titania nanotube arrays with enhanced photocatalytic reduction of $\mathrm{CO}_{2}$ into $\mathrm{CH}_{4}$. Nanoscale Res. Lett. 2014, 9, 272. [CrossRef] [PubMed]

94. Zhang, M.; Lu, D.; Yan, G.; Wu, J.; Yang, J. Fabrication of Mo+N-codoped $\mathrm{TiO}_{2}$ nanotube arrays by anodization and sputtering for visible light-induced photoelectrochemical and photocatalytic properties. J. Nanomater. 2013, 12, 156.

95. Yang, Y.; Hoffmann, M.R. Synthesis and stabilization of blue-black $\mathrm{TiO}_{2}$ nanotube arrays for electrochemical oxidant generation and wastewater treatment. Environ. Sci. Technol. 2016, 50, 11888-11894. [CrossRef] [PubMed]

96. Cho, K.; Lee, S.; Kim, H.; Kim, H.-E.; Son, A.; Kim, E.-J.; Li, M.; Qiang, Z.; Hong, S.W. Effects of reactive oxidants generation and capacitance on photoelectrochemical water disinfection with self-doped titanium dioxide nanotube arrays. Appl. Catal. B Environ. 2019, 257, 117910. [CrossRef]

97. Liu, N.; Haeublein, V.; Zhou, X.; Venkatesan, U.; Hartmann, M.; MacKovic, M.; Nakajima, T.; Spiecker, E.; Osvet, A.; Frey, L.; et al. "Black" $\mathrm{TiO}_{2}$ nanotubes formed by high-energy proton implantation show noble-metal-co-catalyst free photocatalytic $\mathrm{H}_{2}$-evolution. Nano Lett. 2015, 15, 6815-6820. [CrossRef]

98. Zhou, X.; Häublein, V.; Liu, N.; Nguyen, N.T.; Zolnhofer, E.M.; Tsuchiya, H.; Killian, M.S.; Meyer, K.; Frey, L.; Schmuki, P. $\mathrm{TiO}_{2}$ nanotubes: Nitrogen-ion implantation at low dose provides noble-metal-free photocatalytic $\mathrm{H}_{2}$-evolution activity. Angew. Chem. Int. Ed. 2016, 55, 3763-3767. [CrossRef]

99. Liu, N.; Zhou, X.; Nguyen, N.T.; Peters, K.; Zoller, F.; Hwang, I.; Schneider, C.; Miehlich, M.E.; Freitag, D.; Meyer, K.; et al. Black magic in gray titania: Noble-metal-free photocatalytic $\mathrm{H}_{2}$ evolution from hydrogenated anatase. ChemSusChem 2017, 10, 62-67. [CrossRef] 
100. Mattox, D.M. Handbook of Physical Vapor Deposition (PVD) Processing, 2nd ed.; William Andrew: Cambridge, MA, USA, 2010; pp. 1-24. ISBN 978-0-8155-2037-5.

101. Lee, W.; Park, S.-J. Porous anodic aluminum oxide: Anodization and templated synthesis of functional nanostructures. Chem. Rev. 2014, 114, 7487-7556. [CrossRef]

102. Lai, C.W.; Sreekantan, S. Photoelectrochemical response studies of $\mathrm{W}$ deposited $\mathrm{TiO}_{2}$ nanotubes via thermal evaporation technique. J. Exp. Nanosci. 2014, 9, 728-738. [CrossRef]

103. Zhou, X.; Licklederer, M.; Schmuki, P. Thin $\mathrm{MoS}_{2}$ on $\mathrm{TiO}_{2}$ nanotube layers: An efficient co-catalyst/harvesting system for photocatalytic $\mathrm{H}_{2}$ evolution. Electrochem. Commun. 2016, 73, 33-37. [CrossRef]

104. Chung, C.K.; Tu, K.T.; Chang, C.Y.; Peng, Y.C. Fabrication of thin-film spherical anodic alumina oxide templates using a superimposed nano-micro structure. Surf. Coat. Technol. 2019, 361, 170-175. [CrossRef]

105. Spanu, D.; Recchia, S.; Mohajernia, S.; Tomanex, O.; Kment, S.; Zboril, R.; Schmuki, P.; Altomare, M. Templated dewetting-alloying of $\mathrm{NiCu}$ bilayers on $\mathrm{TiO}_{2}$ nanotubes enables efficient noble-metal-free photocatalytic $\mathrm{H}_{2}$ evolution. ACS Catal. 2018, 8, 5298-5305. [CrossRef]

106. Bjelajac, A.; Djokic, V.; Petrovic, R.; Socol, G.; Mihailescu, I.N.; Florea, I.; Ersen, O.; Janackovic, D. Visible light-harvesting of $\mathrm{TiO}_{2}$ nanotubes array by pulsed laser deposition CdS. Appl. Surf. Sci. 2014, 309, 225-230. [CrossRef]

107. Nasirpouri, F. Fundamentals and principles of electrode-position. In Electrodeposition of Nanostructured Materials; Springer International Publishing: Cham, Switzerland, 2017; Volume 62, pp. 75-121. ISBN 978-3-319-44920-3.

108. Yliniemi, K.; Nguyen, N.T.; Mohajemia, S.; Liu, N.; Wilson, B.P.; Schmuki, P.; Lundström, M. A direct synthesis of platinum/nickel co-catalysts on titanium dioxide nanotube surface from hydrometallurgical-type process streams. J. Clean. Prod. 2018, 201, 39-48. [CrossRef]

109. Li, Y.; Yu, H.; Zhang, C.; Fu, L.; Li, G.; Shao, Z.; Yi, B. Electrodeposition of $\mathrm{Ni}$ oxide on $\mathrm{TiO}_{2}$ nanotube arrays for enhancing visible light photoelectrochemical water splitting. J. Electroanal. Chem. 2013, 688, 228-231. [CrossRef]

110. Xiao, F.-X.; Hung, S.-F.; Tao, H.B.; Miao, J.; Yang, H.B.; Liu, B. Spatially branched hierarchical ZnO nanorod- $\mathrm{TiO}_{2}$ nanotube array heterostructures for versatile photocatalytic and photoelectrocatalytic applications: Towards intimate integration of 1D-1D hybrid nanostructures. Nanoscale 2014, 6, 14950-14961. [CrossRef]

111. Muneshwar, T.; Miao, M.; Borujeny, E.R.; Cadien, K. Atomic layer deposition: Fundamentals, practice and challenges. In Handbook of Thin Film Deposition, 4th ed.; Seshan, K., Schepis, D., Eds.; William Andrew: Cambridge, MA, USA, 2018; pp. 359-373. ISBN 978-0-12-812311-9.

112. Elam, J.; Routkevitch, D.; Mardilovich, P.; George, S. Conformal coating on ultrahigh-aspect-ratio nanopores of anodic alumina by atomic layer deposition. Chem. Mater. 2003, 15, 3507-3517. [CrossRef]

113. Johnson, R.W.; Hultqvist, A.; Bent, S.F. A brief review of atomic layer deposition: From fundamentals to applications. Mater. Today 2014, 17, 236-246. [CrossRef]

114. Leskelä, M.; Ritala, M. Atomic layer deposition chemistry: Recent developments and future challenges. Angew. Chem. Int. Ed. 2003, 42, 5548-5554. [CrossRef]

115. Turkevych, I.; Kosar, S.; Pihosh, Y.; Mawatari, K.; Kitamori, T.; Ye, J.; Shimamura, K. Synergetic effect between $\mathrm{TiO}_{2}$ and ubiquitous metal oxides on photocatalytic activity of composite nanostructures. J. Ceram. Soc. Jpn. 2014, 122, 393-397. [CrossRef]

116. Ng, S.; Krbal, M.; Zaxpe, R.; Prikryl, J.; Charvot, J.; Dvořák, F.; Strizik, L.; Slang, S.; Sopha, H.; Kosto, $\mathrm{Y}$; , et al. $\mathrm{MoSe}_{\mathrm{x}} \mathrm{O}_{\mathrm{y}}$-coated $1 \mathrm{D} \mathrm{TiO}$ nanotube layers: Efficient interface for light-driven applications. Adv. Mater. Interfaces 2018, 5, 1701146. [CrossRef]

117. Yoo, J.; Zazpe, R.; Cha, G.; Prikryl, J.; Hwang, I.; Macak, J.M.; Schmuki, P. Uniform ALD deposition of Pt nanoparticles within $1 \mathrm{D}$ anodic $\mathrm{TiO}_{2}$ nanotubes for photocatalytic $\mathrm{H}_{2}$ generation. Electrochem. Commun. 2018, 86, 6-11. [CrossRef]

118. Danks, A.; Hall, S.; Schnepp, Z. The evolution of 'sol-gel'chemistry as a technique for materials synthesis. Mater. Horiz. 2016, 3, 91-112. [CrossRef]

119. Owens, G.J.; Singh, R.K.; Foroutan, F.; Alqaysi, M.; Han, C.-M.; Mahapatra, C.; Kim, H.-W.; Knowles, J.C. Sol-gel based materials for biomedical applications. Prog. Mater. Sci. 2016, 77, 1-79. [CrossRef]

120. Figueira, R.; Silva, C.J.; Pereira, E. Organic-inorganic hybrid sol-gel coatings for metal corrosion protection: A review of recent progress. J. Coat. Technol. Res. 2015, 12, 1-35. [CrossRef] 
121. Clark Wooten, M.K.; Koganti, V.R.; Zhou, S.; Rankin, S.E.; Knutson, B.L. Synthesis and nanofiltration membrane performance of oriented mesoporous silica thin films on macroporous supports. ACS Appl. Mater. Inter. 2016, 8, 21806-21815. [CrossRef]

122. Qu, X.; Xie, D.; Gao, L.; Cao, L.; Du, F. Synthesis and characterization of $\mathrm{TiO}_{2} / \mathrm{WO}_{3}$ composite nanotubes for photocatalytic applications. J. Mater. Sci. 2015, 50, 21-27. [CrossRef]

123. Nguyen, N.T.; Ozkan, S.; Hejazi, S.; Denisov, N.; Tomanec, O.; Zboril, R.; Schmuki, P. Providing significantly enhanced photocatalytic $\mathrm{H}_{2}$ generation using porous PtPdAg alloy nanoparticles on spaced $\mathrm{TiO}_{2}$ nanotubes. Int. J. Hydrog. Energy 2019, 44, 22962-22971. [CrossRef]

124. Sanabria-Arenas, B.E.; Mazare, A.; Yoo, J.; Nguyen, N.T.; Hejazi, S.; Bian, H.; Diamanti, M.V.; Pedeferri, M.P.; Schmuki, P. Intrinsic AuPt-alloy particles decorated on $\mathrm{TiO}_{2}$ nanotubes provide enhanced photocatalytic degradation. Electrochim. Acta 2018, 292, 865-870. [CrossRef]

125. Hu, Z.; Chen, D.; Zhan, X.; Wang, F.; Qin, L.; Huang, Y. Synthesis of Ag-loaded $\mathrm{SrTiO}_{3} / \mathrm{TiO}_{2}$ heterostructure nanotube arrays for enhanced photocatalytic performances. Appl. Phys. A 2017, 123, 399. [CrossRef]

126. Kontos, A.I.; Likodimos, V.; Stergiopoulos, T.; Tsoukleris, D.S.; Falaras, P.; Rabias, I.; Papavassiliou, G.; Kim, D.; Kunze, J.; Schmuki, P. Self-organized anodic $\mathrm{TiO}_{2}$ nanotube arrays functionalized by iron oxide nanoparticles. Chem. Mater. 2009, 21, 662-672. [CrossRef]

127. Zhao, X.; Liu, H.; Qu, J. Photoelectrocatalytic degradation of organic contaminants at $\mathrm{Bi}_{2} \mathrm{O}_{3} / \mathrm{TiO}_{2}$ nanotube array electrode. Appl. Surf. Sci. 2011, 257, 4621-4624. [CrossRef]

128. Yang, H.Y.; Yu, S.F.; Lau, S.P.; Zhang, X.; Sun, D.D.; Jun, G. Direct growth of ZnO nanocrystals onto the surface of porous $\mathrm{TiO}_{2}$ nanotube arrays for highly efficient and recyclable photocatalysts. Small 2009, 5, 2260-2264. [CrossRef]

129. Liu, Y.; Zhang, X.; Liu, R.; Yang, R.; Liu, C.; Cai, Q. Fabrication and photocatalytic activity of high-efficiency visible-light-responsive photocatalyst $\mathrm{ZnTe} / \mathrm{TiO}_{2}$ nanotube arrays. J. Solid State Chem. 2011, 184, 684-689. [CrossRef]

130. Mazierski, P.; Nadolna, J.; Nowaczyk, G.; Lisowski, W.; Winiarski, M.J.; Klimczuk, T.; Kobylański, M.P.; Jurga, S.; Zaleska-Medynska, A. Highly visible-light-photoactive heterojunction based on $\mathrm{TiO}_{2}$ nanotubes decorated by $\mathrm{Pt}$ nanoparticles and $\mathrm{Bi}_{2} \mathrm{~S}_{3}$ quantum dots. J. Phys. Chem. C 2017, 121, 17215-17225. [CrossRef]

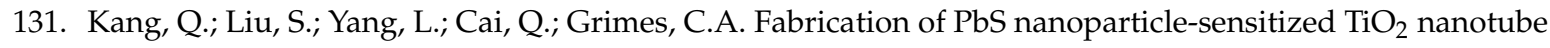
arrays and their photoelectrochemical properties. ACS Appl. Mater. Interfaces 2011, 3, 746-749. [CrossRef]

132. Zhang, M.; Gong, Z.; Tao, J.; Wang, X.; Wang, Z.; Yang, L.; He, G.; Lv, J.; Wang, P.; Fing, Z.; et al. Effect of ZnS layers on optical properties of prepared $\mathrm{CdS} / \mathrm{TiO}_{2}$ nanotube arrays for photocatalyst. J. Nanoparticle Res. 2017, 19, 120. [CrossRef]

133. Yang, L.; Luo, S.; Liu, R.; Cai, Q.; Xiao, Y.; Liu, S.; Su, F.; Wen, L. Fabrication of CdSe nanoparticles sensitized long $\mathrm{TiO}_{2}$ nanotube arrays for photocatalytic degradation of anthracene-9-carboxylic acid under green monochromatic light. J. Phys. Chem. C 2010, 114, 4783-4789. [CrossRef]

134. Lin, J.; Zong, R.; Zhou, M.; Zhu, Y. Photoelectric catalytic degradation of methylene blue by C60-modified $\mathrm{TiO}_{2}$ nanotube array. Appl. Catal. B 2009, 89, 425-431. [CrossRef]

135. Liu, C.; Teng, Y.; Liu, R.; Luo, S.; Tang, Y.; Chen, L.; Cai, Q. Fabrication of graphene films on $\mathrm{TiO}_{2}$ nanotube arrays for photocatalytic application. Carbon 2011, 49, 5312-5320. [CrossRef]

136. Yu, J.; Dai, G.; Huang, B. Fabrication and characterization of visible-light-driven plasmonic photocatalyst $\mathrm{Ag} / \mathrm{AgCl} / \mathrm{TiO}_{2}$ nanotube arrays. J. Phys. Chem. C 2009, 113, 16394-16401. [CrossRef]

137. Shrestha, N.K.; Yang, M.; Paramasivam, I.; Schmuki, P. Visible-light-induced photocatalysis using self-organized $\mathrm{TiO}_{2}$ nanotubes decorated with AgBr deposits. Semicond. Sci. Technol. 2011, 26, 092002. [CrossRef]

138. Liu, J.; Ruan, L.; Adeloju, S.B.; Wu, Y. BiOI/TiO 2 nanotube arrays, a unique flake-tube structured p-n junction with remarkable visible-light photoelectrocatalytic performance and stability. Dalton Trans. 2014, 43, 1706-1715. [CrossRef] [PubMed]

139. Yablonovitch, E. Inhibited spontaneous emission in solid-state physics and electronics. Phys. Rev. Lett. 1987, 58, 2059-2062. [CrossRef]

140. John, S. Strong localization of photons in certain disordered dielectric superlattices. Phys. Rev. Lett. 1987, 58, 2486-2489. [CrossRef]

141. Santos, A.; Kumeria, T.; Losic, D. Optically optimized photoluminescent and interferometric biosensors based on nanoporous anodic alumina: A comparison. Anal. Chem. 2013, 85, 7904-7911. [CrossRef] 
142. Law, C.S.; Sylvia, G.M.; Nemati, M.; Yu, J.; Losic, D.; Abell, A.D.; Santos, A. Engineering of surface chemistry for enhanced sensitivity in nanoporous interferometric sensing platforms. ACS Appl. Mater. Interfaces 2017, 9, 8929-8940. [CrossRef]

143. Law, C.S.; Lim, S.Y.; Abell, A.D.; Santos, A. Real-time binding monitoring between human blood proteins and heavy metal ions in nanoporous anodic alumina photonic crystals. Anal. Chem. 2018, 90, 10039-10048. [CrossRef]

144. Kumeria, T.; Santos, A.; Rahman, M.M.; Ferré-Borrull, J.; Marsal, L.F.; Losic, D. Advanced structural engineering of nanoporous photonic structures: Tailoring nanopore architecture to enhance sensing properties. ACS Photonics 2014, 1, 1298-1306. [CrossRef]

145. Chen, Y.; Santos, A.; Wang, Y.; Kumeria, T.; Ho, D.; Li, J.; Wang, C.; Losic, D. Rational design of photonic dust from nanoporous anodic alumina films: A versatile photonic nanotool for visual sensing. Sci. Rep. 2015, 5, 12893. [CrossRef] [PubMed]

146. Chen, Y.; Santos, A.; Wang, Y.; Kumeria, T.; Li, J.; Wang, C.; Losic, D. Biomimetic nanoporous anodic alumina distributed Bragg reflectors in the form of films and microsized particles for sensing applications. ACS Appl. Mater. Interfaces 2015, 7, 19816-19824. [CrossRef] [PubMed]

147. Kumeria, T.; Rahman, M.M.; Santos, A.; Ferré-Borrull, J.; Marsal, L.F.; Losic, D. Nanoporous anodic alumina rugate filters for sensing of ionic mercury: Toward environmental point-of-analysis systems. ACS Appl. Mater. Interfaces 2014, 6, 12971-12978. [CrossRef] [PubMed]

148. Santos, A.; Yoo, J.H.; Rohatgi, C.V.; Kumeria, T.; Wang, Y.; Losic, D. Realisation and advanced engineering of true optical rugate filters based on nanoporous anodic alumina by sinusoidal pulse anodisation. Nanoscale 2016, 8, 1360-1373. [CrossRef]

149. Eckstein, C.; Law, C.S.; Lim, S.Y.; Kaur, S.; Kumeria, T.; Ferré-Borrull, J.; Abell, A.D.; Marsal, L.F.; Santos, A. Nanoporous photonic crystals with tailored surface chemistry for ionic copper sensing. J. Mater. Chem. C 2019, 7, 12278-12289. [CrossRef]

150. Wang, G.; Wang, J.; An, Y.; Wang, C. Anodization fabrication of $3 \mathrm{D} \mathrm{TiO} 2$ photonic crystals and their application for chemical sensors. Supperlattice Microst. 2016, 100, 290-295. [CrossRef]

151. Ye, M.; Xin, X.; Lin, C.; Lin, Z. High efficiency dye-sensitized solar cells based on hierarchically structured nanotubes. Nano Lett. 2011, 11, 3214-3220. [CrossRef]

152. Guo, M.; Xie, K.; Lin, J.; Yong, Z.; Yip, C.T.; Zhou, L.; Wang, Y.; Huang, H. Design and coupling of multifunctional $\mathrm{TiO}_{2}$ nanotube photonic crystal to nanocrystalline titania layer as semi-transparent photoanode for due-sensitized solar cell. Energy Environ. Sci. 2012, 5, 9881-9888. [CrossRef]

153. Yip, C.T.; Huang, H.; Zhou, L.; Xie, K.; Wang, Y.; Feng, T.; Li, J.; Tam, W.Y. Direct and seamless coupling of $\mathrm{TiO}_{2}$ nanotube photonic crystal to dye-sensitized solar cell: A single-step approach. Adv. Mater. 2011, 23, 5624-5628. [CrossRef]

154. Wijnhoven, J.E.G.J.; Vos, W.L. Preparation of photonic crystals made of air spheres in Titania. Science 1998, 281, 802-804. [CrossRef]

155. Liu, J.; Zhao, H.; Wu, M.; Van der Schueren, B.; Li, Y.; Deparis, O.; Ye, J.; Ozin, G.A.; Hasan, T.; Su, B.-L. Slow photons for photocatalysis and photovoltaics. Adv. Mater. 2017, 29, 1605349. [CrossRef]

156. Santos, A.; Deen, M.J.; Marsal, L.F. Low-cost fabrication technologies for nanostructures: State-of-the-art and potential. Nanotechnology 2015, 26, 042001. [CrossRef]

157. Dai, X.-C.; Hou, S.; Huang, M.-H.; Li, Y.-B.; Li, T.; Xiao, F.-X. Electrochemically anodized one-dimensional semiconductors: A fruitful platform for solar energy conversion. J. Phys. Energy 2019, 1, 022002. [CrossRef]

158. Wang, Y.; Chen, Y.; Kumeria, T.; Ding, F.; Evdokiou, A.; Losic, D.; Santos, A. Facile synthesis of optical microcavities by a rationally designed anodization approach: Tailoring photonic signals by nanopore structure. ACS Appl. Mater. Interfaces 2015, 7, 9879-9888. [CrossRef]

159. Law, C.S.; Lim, S.Y.; Macalincag, R.M.; Abell, A.D.; Santos, A. Light-confining nanoporous anodic alumina microcavities by apodized stepwise pulse anodization. ACS Appl. Nano Mater. 2018, 1, 4418-4434. [CrossRef]

160. Law, C.S.; Lim, S.Y.; Abell, A.D.; Marsal, L.F.; Santos, A. Structural tailoring of nanoporous anodic alumina optical microcavities for enhanced resonant recirculation of light. Nanoscale 2018, 10, 14139-14152. [CrossRef]

161. Law, C.S.; Lim, S.Y.; Santos, A. On the precise tuning of optical filtering features in nanoporous anodic alumina distributed Bragg reflectors. Sci. Rep. 2018, 8, 4642. [CrossRef] 
162. Santos, A.; Law, C.S.; Lei, D.W.C.; Pereira, T.; Losic, D. Fine tuning of optical signals in nanoporous anodic alumina photonic crystals by apodized sinusoidal pulse anodisation. Nanoscale 2016, 8, 18360-18375. [CrossRef]

163. Lim, S.Y.; Law, C.S.; Marsal, L.F.; Santos, A. Engineering of hybrid nanoporous anodic alumina photonic crystals by heterogeneous pulse anodization. Sci. Rep. 2018, 8, 9455. [CrossRef]

164. Lin, J.; Liu, K.; Chen, X. Synthesis of periodically structured Titania nanotube films and their potential for photonic applications. Small 2011, 7, 1784-1789. [CrossRef]

165. Sapoletova, N.A.; Kushnir, S.E.; Napolskii, K.S. Anodic titanium oxide photonic crystals prepared by novel cyclic anodizing with voltage versus charge modulation. Electrochem. Commun. 2018, 91, 5-9. [CrossRef]

166. Guo, M.; Xie, K.; Wang, Y.; Zhou, L.; Huang, H. Aperiodic $\mathrm{TiO}_{2}$ nanotube photonic crystal: Full-visible-spectrum solar light harvesting in photovoltaic devices. Sci. Rep. 2014, 4, 6442. [CrossRef] [PubMed]

167. Suhaimy, S.H.M.; Lai, C.W.; Tajuddin, H.A.; Samsudin, E.M.; Johan, M.R. Impact of $\mathrm{TiO}_{2}$ nanotubes' morphology on the photocatalytic degradation of simazine pollutant. Materials 2018, 11, 2066. [CrossRef]

168. Ye, Y.; Bruning, H.; Liu, W.; Rijnaarts, H.; Yntema, D. Effect of dissolved natural organic matter on the photocatalytic micropollutant removal performance of $\mathrm{TiO}_{2}$ nanotube array. J. Photochem. Photobiol. A 2019, 371, 216-222. [CrossRef]

169. Ye, Y.; Feng, Y.; Bruning, H.; Yntema, D.; Rijnaarts, H.H.M. Photocatalytic degradation of metoprolol by $\mathrm{TiO}_{2}$ nanotube arrays and UV-LED: Effects of catalyst properties, operational parameters, commonly present water constituents, and photo-induced reactive species. Appl. Catal. B Environ. 2018, 220,171-181. [CrossRef]

170. Gomes, J.; Lincho, J.; Domingues, E.; Gmurek, M.; Mazierski, P.; Zaleska-Medynska, A.; Klimczuk, T.; Quinta-Ferreira, R.M.; Martins, R.C. $\mathrm{TiO}_{2}$ nanotube arrays-based reactor for photocatalytic oxidation of paraben mixtures in ultrapure water: Effects of photocatalyst properties, operational parameters and light source. Sci. Total Environ. 2019, 689, 79-89. [CrossRef]

171. Wang, N.; Li, X.; Wang, Y.; Quan, X.; Chen, G. Evaluation of bias potential enhanced photocatalytic degradation of 4-chlorophenol with $\mathrm{TiO}_{2}$ nanotube fabricated by anodic oxidation method. Chem. Eng. J. 2009, 146, 30-35. [CrossRef]

172. Quan, X.; Ruan, X.; Zhao, H.; Chen, S.; Zhao, Y. Photoelectrocatalytic degradation of pentachlorophenol in aqueous solution using a $\mathrm{TiO}_{2}$ nanotube film electrode. Environ. Pollut. 2007, 147, 409-414. [CrossRef]

173. Arenas, B.E.S.; Strini, A.; Schiavi, L.; Bassi, A.L.; Russo, V.; Curto, B.D.; Diamanti, M.V.; Pedeferri, M. Photocatalytic activity of nanotubular $\mathrm{TiO}_{2}$ films obtained by anodic oxidation: A comparison in gas and liquid phase. Materials 2018, 11, 488. [CrossRef]

174. Pichat, $\mathrm{P}$. Are $\mathrm{TiO}_{2}$ nanotubes worth using in photocatalytic purification of air and water? Molecules 2014, 19, 15075-15087. [CrossRef]

175. Nevárez-Martínez, M.C.; Kobylánski, M.P.; Mazierski, P.; Wółkiewicz, J.; Trykowski, G.; Malankowska, A.; Kozak, M.; Espinoza-Montero, P.J.; Zaleska-Medynska, A. Self-organized $\mathrm{TiO}_{2}-\mathrm{MnO}_{2}$ nanotube arrays for efficient photocatalytic degradation of toluene. Molecules 2017, 22, 564. [CrossRef] [PubMed]

176. Yang, L.; Xiao, Y.; Liu, S.; Li, Y.; Cai, Q.; Luo, S.; Zeng, G. Photocatalytic reduction of Cr(VI) on $\mathrm{WO}_{3}$ doped long $\mathrm{TiO}_{2}$ nanotube arrays in the presence of citric acid. Appl. Catal. B Environ. 2010, 94, 142-149. [CrossRef]

177. Schulte, K.L.; DeSario, P.A.; Gray, K.A. Effect of crystal phase composition on the reductive and oxidative abilities of $\mathrm{TiO}_{2}$ nanotubes under UV and visible light. Appl. Catal. B Environ. 2010, 97, 354-360. [CrossRef]

178. Kar, P.; Zeng, S.; Zhang, Y.; Vahidzadeh, E.; Manuel, A.; Kisslinger, R.; Alam, K.M.; Thakur, U.K.; Mahdi, N.; Kumar, P.; et al. High rate $\mathrm{CO}_{2}$ photoreduction using flame annealed $\mathrm{TiO}_{2}$ nanotubes. Appl. Catal. B Environ. 2019, 243, 522-536. [CrossRef]

179. Lee, K.; Mazare, A.; Schmuki, P. One-dimensional titanium dioxide nanomaterials: Nanotubes. Chem. Rev. 2014, 114, 9385-9454. [CrossRef]

180. Song, Y.Y.; Roy, P.; Paramasivam, I.; Schmuki, P. Voltage-induced payload release and wettability control on $\mathrm{TiO}_{2}$ and $\mathrm{TiO}_{2}$ nanotubes. Angew. Chem. Int. Ed. 2010, 49, 351-354. [CrossRef]

181. Song, Y.; Schmidt-stein, F.; Bauer, S.; Schmuki, P. Amphiphilic $\mathrm{TiO}_{2}$ nanotube arrays: An actively controllable drug delivery system. J. Am. Chem. Soc. 2009, 131, 4230-4232. [CrossRef]

182. Shrestha, N.K.; Macak, J.M.; Schmidt-Stein, F.; Hahn, R.; Mierke, C.T.; Fabry, B.; Schmuki, P. Magnetically guided Titania nanotubes for site-selective photocatalysis and drug release. Angew. Chem. Int. Ed. 2009, 48, 969-972. [CrossRef] 
183. Kalbacova, M.; Macak, J.M.; Schmidt-Stein, F.; Mierke, C.T.; Schmuki, P. $\mathrm{TiO}_{2}$ nanotubes: Photocatalyst for cancer cell killing. Phys. Stat. Sol. (RRL) 2008, 2, 194-196. [CrossRef]

184. Faraji, M.; Mohaghegh, N.; Abedini, A. $\mathrm{TiO}_{2}$ nanotubes/Ti Plates modified by silver-benzene with enhanced photocatalytic antibacterial properties. New J. Chem. 2018, 42, 2058-2066. [CrossRef]

185. Jiang, W.; He, J.; Zhong, J.; Lu, J.; Yuan, S.; Liang, B. Preparation and photocatalytic performance of $\mathrm{ZrO}_{2}$ nanotubes fabricated with anodization process. Appl. Surf. Sci. 2014, 307, 407-413. [CrossRef]

186. Cristino, V.; Caramori, S.; Argazzi, R.; Meda, L.; Marra, G.L.; Bignozzi, C.A. Efficient photoelectrochemical water splitting by anodically grown $\mathrm{WO}_{3}$ electrodes. Langmuir 2011, 27, 7276-7284. [CrossRef] [PubMed]

187. Lai, C.W.; Hamid, S.B.A.; Sreekantan, S. A novel solar driven photocatalyst: Well-aligned anodic $\mathrm{WO}_{3}$ nanotubes. Int. J. Photoenergy 2013, 2013, 745301. [CrossRef]

188. Liu, Y.; Meng, H.; Yu, X.; Zhu, Y.; Zhang, Y. Photocatalytic film of BiOCl honeycomb array from anodic aluminium oxide template. Mater. Technol. Adv. Func. Mater. 2015, 30, A84-A88. [CrossRef]

(C) 2019 by the authors. Licensee MDPI, Basel, Switzerland. This article is an open access article distributed under the terms and conditions of the Creative Commons Attribution (CC BY) license (http://creativecommons.org/licenses/by/4.0/). 